\title{
WestVirginiaUniversity
}

THE RESEARCH REPOSITORY @ WVU

Graduate Theses, Dissertations, and Problem Reports

2008

\section{Effects of aging and gender on vasoreactivity of coronary arterioles}

Amanda Jo LeBlanc

West Virginia University

Follow this and additional works at: https://researchrepository.wvu.edu/etd

\section{Recommended Citation}

LeBlanc, Amanda Jo, "Effects of aging and gender on vasoreactivity of coronary arterioles" (2008).

Graduate Theses, Dissertations, and Problem Reports. 4395.

https://researchrepository.wvu.edu/etd/4395

This Dissertation is protected by copyright and/or related rights. It has been brought to you by the The Research Repository @ WVU with permission from the rights-holder(s). You are free to use this Dissertation in any way that is permitted by the copyright and related rights legislation that applies to your use. For other uses you must obtain permission from the rights-holder(s) directly, unless additional rights are indicated by a Creative Commons license in the record and/ or on the work itself. This Dissertation has been accepted for inclusion in WVU Graduate Theses, Dissertations, and Problem Reports collection by an authorized administrator of The Research Repository @ WVU.

For more information, please contact researchrepository@mail.wvu.edu. 
Effects of Aging and Gender on Vasoreactivity of Coronary Arterioles

Amanda Jo LeBlanc

Dissertation submitted to the

School of Medicine

at West Virginia University

in partial fulfillment of the requirements

for the degree of

Doctor of Philosophy

in

Exercise Physiology

Judy M. Muller-Delp, Ph.D., Chair

Michael D. Delp, Ph.D.

S. Jamal Mustafa, Ph.D.

Robert A. Dailey, Ph.D.

Jefferson C. Frisbee, Ph.D.

Division of Exercise Physiology

Morgantown, West Virginia

2008

Keywords: Microcirculation, Flow-induced Vasodilation, Endothelin 


\section{ABSTRACT \\ Effects of Aging and Gender on Vasoreactivity of Coronary Arterioles}

\section{Amanda Jo LeBlanc}

The purpose of the first study was to determine how age and ovarian hormones affect flow-induced vasodilation in the coronary microcirculation. Coronary arterioles were isolated from young, middle-aged, and old control, ovariectomized (OVX) and ovariectomized + estrogen replaced (OVE) female Fischer-344 rats to assess vasodilation to increases in flow. L-NAME, a nitric oxide synthase (NOS) inhibitor, was used to assess NO contribution to flow-induced dilation (FID). FID of coronary arterioles was impaired with advancing age. Ovariectomy reduced FID in young females only; however, estrogen-replacement restored or improved FID in all age groups. FID was reduced after pretreatment with L-NAME in young control and all estrogen-replaced groups, indicating these dilator responses were mediated through nitric oxide (NO). Increasing age caused an impairment of FID which corresponds to an age-related loss in NO-mediated dilation in the coronary microcirculation of female rats. FID in aged females appears to be impervious to OVX; however, estrogen-replacement improves FID by $\sim 160 \%$ versus old control and OVX.

The second study evaluated vasoconstriction to endothelin in coronary arterioles from young and old male and female Fischer-344 rats. BQ123, an ETa receptor inhibitor, or $\mathrm{BQ788}$, an ETb receptor inhibitor, was used to assess receptor-specific contributions to ET-induced vasoconstriction in intact and endothelium-denuded arterioles. Males exhibited an age-related decline in vasoconstriction to ET in coronary arterioles which is associated with a decline in ETa receptor mRNA and protein expression. Arterioles from females demonstrated increased ET-induced vasoconstriction with advancing age, but this is not associated with an age-related alteration in ETa or ETb receptor mRNA or protein expression. Aging differentially alters vasoconstriction to ET in coronary arterioles from males and females, and this may contribute to the gender-related differences in the development of cardiovascular risk with aging. 


\section{ACKNOWLEDGMENTS}

I would like to thank my committee members for their time, input, and guidance the past couple years. Thank you for helping me think "outside the box", even though it was extremely painful to do sometimes. You've helped me grow as a scientist and shed light on how much I still have to learn. Thank you Judy, for taking me in as a student, mentoring me, and giving me valuable tools to succeed in our vessel world. You are a brilliant scientist that I will continually strive to become an equal. Also, I want to thank you for staying here at WVU to see me finish my $\mathrm{PhD}$. Without your decision, I would not have been able to finish and begin the next phase of my career.

I want to extend my gratitude to my friends that I've met here in Morgantown. They certainly have assisted in adequate stress relief and have given me an outlet for ranting and raving about all the unfairness that life seemed to throw at me. They are great company for happy hours, camping, or sitting on the deck trying out new recipes and wines.

My family has always given me the utmost support and love through all my years of school. Even though they still can't remember what program I was in, or what my degree title is, they continually tell me how proud they are of me and in turn, that gives me the will to fight on through the rough patches. My mother has always treated me like an only child, and my siblings have never let me live that down (ha ha). She has continually sacrificed herself for my goals, and there is not enough room in this entire dissertation to thank her enough for everything she has done for me. My sister Shawn has also treated me like an only sister - and our bond could not be stronger. My other sister Angie was the first one in the family to go to college, and I have always revered her 
for that decision. She has been the person I looked up to for guidance when I was younger because she was and still is a successful and smart businesswoman who put her career first. My brother Matt has always been a (good) thorn in my side; prodding, poking, and strongly convincing me that I was heading in the right direction.

Without my husband Blake, I guarantee this dissertation would not have been written. He is my anchor. I would not have made it to this point without him guiding me and helping me handle all the tough situations and struggles that I have endured the last year. Thank you for bearing with me and keeping my eye on the goal of improving our life together. We said we would hold each other up when life became too heavy, and I am grateful for his strong back which has supported me.

Lastly, although my father is no longer with me on earth - he always told me how proud he was of my educational goals. I dedicate this dissertation to him and also to my loving sets of grandparents. I wish I had been able to have more time with all of them once I became an adult - because I didn't truly appreciate all the sacrifices they had made for my family when I was young. 


\section{TABLE OF CONTENTS}

Abstract...................................................................

Acknowledgments.................................................ii

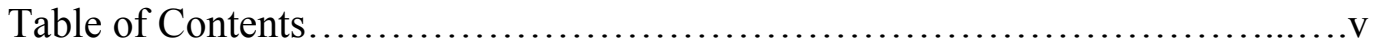

List of Figures.....................................................



List of Symbols.......................................................

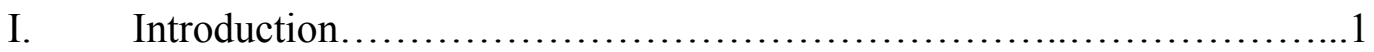

Specific Aims of this Dissertation.......................... 9

II. Study 1: Estrogen-replacement improves while aging and loss of ovarian hormones impair flow-induced vasodilation in coronary



Overview...............................................11

Introduction.............................................. 12

Methods..............................................14

Results..................................................19

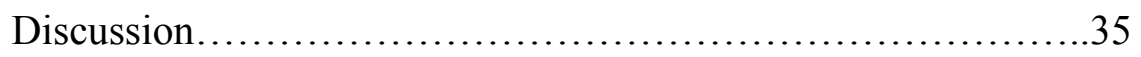

III. Study 2: Aging and gender effects on vasoconstriction to endothelin in



Overview............................................43

Introduction...........................................44

Methods...............................................45

Results................................................50 
Discussion............................................62

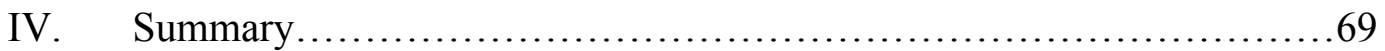

V. References................................................. 71

VI. Appendix..................................................... 80

VII. Curriculum Vitae...............................................85 


\section{LIST OF FIGURES}

Introduction

Figure 1.1 Langendorff-perfused hearts of young and old female Fischer-344 in response to increasing concentrations of Dea-NONOate........3

Study 1.

Figure 2.1 Flow-induced dilation in young, middle-aged and old control females..........................................................

Figure 2.2 Flow-indued dilation in young, middle-aged and old control,

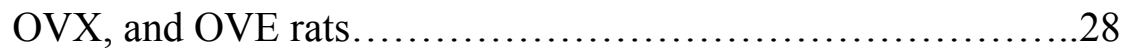

Figure 2.3 Flow-induced dilation in the presence and absence of L-NAME, a NOS inhibitor, in young, middle-age, and old control females.29

Figure 2.4 Flow-induced dilation in the presence and absence of L-NAME, a NOS inhibitor, in young, middle-age, and old OVX females.....30

Figure 2.5 Flow-induced dilation in the presence and absence of L-NAME, a NOS inhibitor, in young, middle-age, and old OVE females.....31

Figure 2.6 Concentration-response curves to Dea-NONOate, an exogenous NO donor................................................. 32

Figure 2.7 mRNA RQ values for AKT and eNOS for all female groups......33

Figure 2.8 Western blot analysis of p-eNOS relative to $\beta$-actin loading control (bar graphs)

Study 2 .

Figure 3.1 Vasoconstriction to ET in coronary arterioles from young and old males and females. .55 
Figure 3.2 ET-induced vasoconstriction in denuded coronary arterioles from young and old males and females. .56

Figure 3.3 Vasoconstriction to ET after pretreatment with BQ123, an ETa receptor inhibitor, or BQ788, an ETb receptor inhibitor, in coronary arterioles from young and old males and females........57

Figure 3.4 ET-induced vasoconstriction in denuded coronary arterioles after inhibition of ETa (BQ123) or ETb (BQ788) receptors in young and old males and females. .58

Figure 3.5 Passive distensibility curves in coronary arterioles from young and old females.

Figure 3.6 ETa and ETb mRNA expression in young and old males and females .60

Figure 3.7 ETa and ETb protein expression in young and old males and females. 


\section{LIST OF TABLES}

Study 1 .

Table 2.1 Animal characteristics of young, middle-aged, and old control,

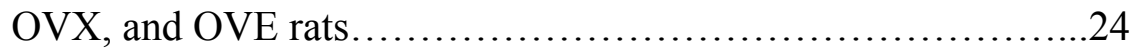

Table 2.2 Vessel characteristics of isolated coronary arterioles in young, middle-aged, and old control, OVX, and OVE rats................25

Table 2.3 Mean slope $(\beta)$ of flow-induced dilation in isolated coronary arterioles in young, middle-aged, and old control, OVX, and OVE rats....................................................

Study 2.

Table 3.1 Animal and vessel characteristics of young and old male and female rats..............................................54 


\section{LIST OF SYMBOLS}

\begin{tabular}{|c|c|}
\hline $\mathrm{ACh}$ & acetylcholine \\
\hline $\mathrm{BW}$ & body weight \\
\hline $\mathrm{COX}$ & cyclooxygenase \\
\hline CVD & cardiovascular disease \\
\hline $\mathrm{D}_{\mathrm{m}}$ & maximal diameter \\
\hline $\mathrm{D}_{\mathrm{s}}$ & steady state diameter measured after intervention \\
\hline $\mathrm{D}_{\mathrm{t}}$ & steady state baseline diameter \\
\hline $\mathrm{ECE}$ & endothelin converting enzyme \\
\hline eNOS & endothelial nitric oxide synthase \\
\hline EDHF & endothelial derived hyperpolarizing factor \\
\hline ER & estrogen receptor \\
\hline ET & endothelin \\
\hline FID & flow-induced dilation \\
\hline HERS & Heart and Estrogen/Progestin Replacement Study \\
\hline HRT & hormone replacement therapy \\
\hline HW & heart weight \\
\hline LAD & left anterior descending artery \\
\hline L-NAME & $\mathrm{N}^{\mathrm{G}}$-nitro-L-arginine methyl ester \\
\hline $\mathrm{NO}$ & nitric oxide \\
\hline NOS & nitric oxide synthase \\
\hline OVE & ovarietomy and estrogen-replacement \\
\hline OVX & ovariectomy \\
\hline
\end{tabular}


PGHS prostaglandin H synthase

PVDF polyvinylidene difluoride

VSM vascular smooth muscle

WHI Women's Health Initiative

$\Delta \mathrm{ID} \quad$ change in internal diameter

$\Delta \mathrm{P}_{\mathrm{IL}} \quad$ incremental change in intraluminal pressure 


\section{CHAPTER I}

\section{INTRODUCTION}

Chronic diseases, genetics, and lifestyle choices all interact to influence the complex process of biological aging. By the year 2030, people 85 years of age and older will constitute the fastest growing segment of our population (1). Cardiovascular disease (CVD) remains the leading cause of death in the United States, claiming more lives each year than the next four leading causes of death combined (111) and the risk for CVD increases with advancing age (56). Therefore, it is imperative to determine how aging affects the cardiovascular system in order to contribute to future therapeutic modalities targeted to CVD.

Cardiac function decreases with advancing age in both humans and animals $(2,3$, 42), and can be affected by both structural and functional changes. Although cardiac output is preserved with age at rest $(23,24,106)$, a multitude of age-related changes occur in the physiological control mechanisms of cardiac function, regardless of gender (57). These include: increased left ventricular wall thickness, decreased peak heart rate and stroke volume $(58,107)$, and a decrease in myocyte number concurrent to an increase in myocyte cell size $(2,116)$.

Efficient ejection of blood from the heart occurs when the afterload of the heart equals that of the vasculature. It has been suggested that the matching of afterloads is

This dissertation follows the style and format of the American Journal of Physiology Heart and Circulatory Physiology. 
conserved when young and is preserved with old age at rest only (58). Age-related cardiac cell-enlargement and subsequent mass increase of the left ventricle contribute to increases in the load of the heart while the vascular load is augmented as a result of arterial stiffening that occurs with advancing age (58). Deficiencies in the ability to meet blood flow demand in the heart or periphery become detrimental when the cardiovascular system is challenged by activities such as exercise or when transitioning from a seated to a standing position. Importantly, the inability of the aged coronary vasculature to provide adequate blood flow in response to increased myocardial demand likely contributes to compromised cardiac function.

Peak cardiac output, heart rate, and stroke volume all decrease with age (58); however, the contribution of age-related alterations in regulation of myocardial blood flow to declining cardiac function remains unclear. The myocardium has a very limited anaerobic tolerance and is dependent on a constant supply of oxygen from the coronary circulation (120). Local metabolic feedback, specifically the production of relaxing and constricting factors, is the primary regulator of coronary blood flow. Due to the high oxygen $\left(\mathrm{O}_{2}\right)$ extraction at rest $(\sim 75 \%)$, increases in cardiac metabolism must be met by an immediate increase in coronary blood flow or myocardial ischemia can occur. The age-related increase in the risk for heart failure may be related to a declining coronary flow reserve that occurs in senescent animals and humans $(19,42)$. Advancing age has previously been shown to cause a $43 \%$ decrease in maximal coronary reserve in isolated hearts of male Fischer 344 rats (42), and recently collected data show a similar reduction in maximal coronary blood flow in senescent female Fischer 344 rats by approximately 24\% (Fig 1.1). Therefore, regardless of gender, the myocardium becomes impaired in its 
ability to increase coronary blood flow in response to changes in cardiac metabolism as age progresses. Aging-induced alterations in coronary vasoreactivity to relaxing or constricting factors may contribute to the age-related decline in coronary vascular reserve and increased risk for heart failure.

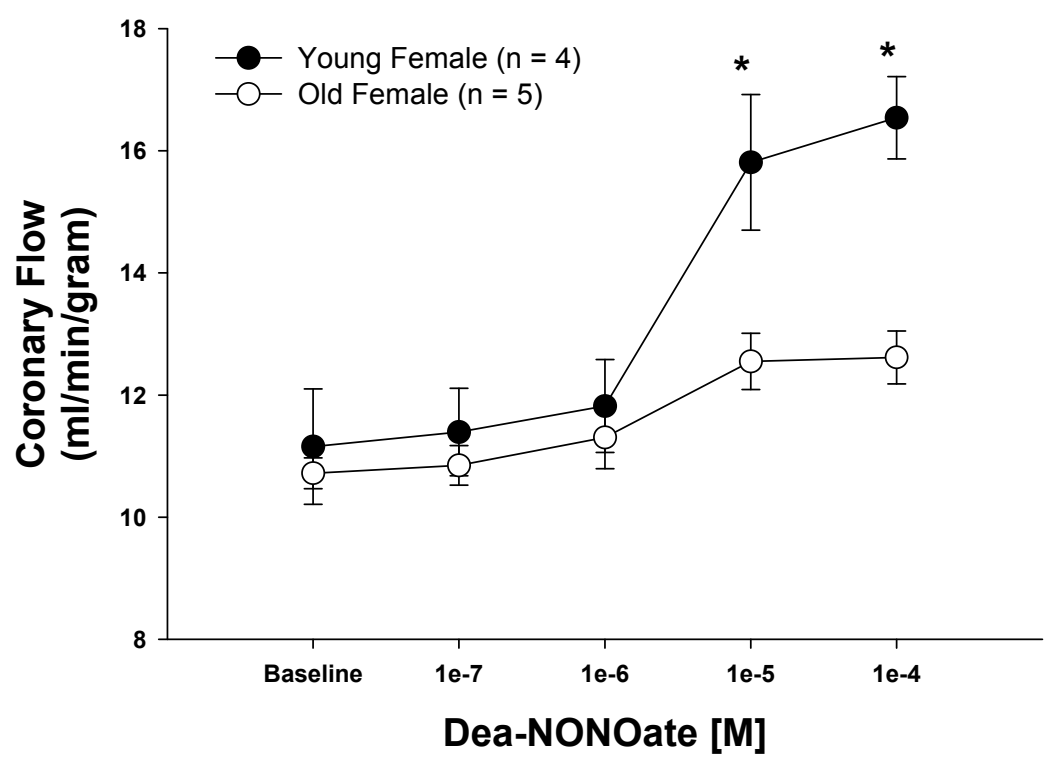

Figure 1.1 The isolated hearts of young and old Fischer 344 females were retrogradely perfused at a constant pressure of $80 \mathrm{mmHg}$ with oxygenated Krebs-Henseleit buffer at $37^{\circ} \mathrm{C}$ in a standard Langendorff preparation and allowed to beat spontaneously. The left ventricle was vented with a small polyethylene apical drain, and a water-filled balloon made of plastic wrap was inserted into the left ventricle across the mitral valve through a left atriotomy. The balloon was connected to a fluid-filled pressure transducer by polyethylene tubing for continuous measurement of left ventricular developed pressure (LVDP). Coronary flow was continuously measured using an ultrasonic flow probe placed in the aortic perfusion line. Basal coronary flow was not different between groups when normalized to heart weight. Young females exhibited greater stimulated increases in coronary flow than old females at higher concentrations of DeaNONOate, an exogenous NO donor. Heart rate was unaffected by increases in coronary flow. ${ }^{*}(\mathrm{P}<0.05)$ Adapted from (110).

Age-induced alterations in vascular function and structure, regardless of gender, create an environment in which CVD can flourish $(57,58)$. Endothelium-dependent vasodilation has been shown to be inversely correlated with aging in large epicardial coronary arteries (27). Vasodilation of coronary arteries decline with age in response to noradrenaline (79), adenosine (45), and testosterone (28). Furthermore, isolated coronary 
arteries from aged male rats have shown an exaggerated vasoconstrictor response to endothelin (51). Therefore, if responsiveness of large coronary arteries to pharmacological stimuli is impaired with increasing age, aging might alter coronary resistance vasculature in a similar manner.

Coronary blood flow is meticulously regulated by the release of a combination of relaxing and constricting factors that help alter blood flow in response to changes in metabolism. Endothelin (ET) functions as a modulator of basal vascular tone in the heart and contributes to coronary blood flow during periods of low metabolism (71). The longlasting vasoconstriction caused by ET can redirect coronary blood flow in order to promote subendocardial perfusion and has been proposed to prevent excessive back flow from the coronary circulation (71). ET mediates its effects via two distinct G-coupled protein receptor subtypes. ETa receptors are the major subtype of receptors involved in the vasoconstrictor response to ET and are localized on the vascular smooth muscle (VSM) cell (66). ETb receptors located on the endothelial cell mediate vasodilation through the release of relaxing factors, but can exert vasoconstriction through ETb receptors located on the smooth muscle (66). Therefore, the net effect of endothelin depends on the relative distribution and density of each specific subtype of receptor.

Considerable heterogeneity exists in the age-related response to ET in the vasculature, and depends on which specific vascular bed is being investigated. For example, a decrease (25), no change (53), or increase (26) in the vasoconstriction to ET with advancing age has been shown in mesenteric arteries, aorta, and gastrocnemius arterioles from male rats, respectively. Thus, vasoconstriction to ET varies between vessels from different vascular beds and between conduit and resistance vessels. This 
laboratory has previously demonstrated a decrease in vasoconstriction to ET with advancing age in coronary arterioles from male rats (97). In contrast, in large coronary arteries from aged male rats, ET-mediated vasoconstriction is increased compared to arteries from young rats $(50,113)$. On the other hand, whole-heart evaluations of ETinduced vasoconstriction have shown no age-related changes (34), which suggests an age-related impairment specific to the microcirculation in male hearts. This decrement in vasoconstriction to ET may contribute to altered blood flow in the hearts of senescent male rats $(42,115)$.

In contrast to the male literature, there are extremely few studies regarding the age-related response to ET in any vascular bed in females. Large epicardial arteries have shown a decrease in maximal constriction to ET in senescent females, but this decline in ET-mediated constriction was associated with an increase in both Big ET and functional endothelin converting enzyme (ECE) activity, two upstream regulators of endothelin production (7). In addition, age-related increases in vasoconstrictor responses to 5-HT in mesenteric arteries (109) and $\mathrm{KCl}$ and norepinephrine (NE) in aortas (7) from females have been reported, along with augmented plasma ET-1 levels in senescent females ( 7 , 11, 122). This suggests that females may exhibit an enhanced vasoconstrictor profile along with an increase in ET levels as age progresses, and this may contribute to altered blood flow regulation as age progresses in females.

Much of the current knowledge of aging effects in the coronary vasculature is confined to large epicardial arteries. Far less is known regarding the effects of age on the vessels which constitute the majority of coronary vascular resistance (i.e., arterioles $<$ $200 \mu \mathrm{m}$ in luminal diameter) (16). Although relatively few studies have investigated this 
important area of research, the first found an impairment in endothelium-dependent vasodilation of septal resistance arteries in middle-aged male rats (18). In addition, vasoconstrictor responses in coronary resistance arterioles were impaired in aged male rats (97). Most studies of vasoreactivity have been on resistance vasculature of the periphery and have shown acetylcholine (ACh)-mediated endothelium-dependent vasodilation is impaired with advancing age in skeletal resistance arteries of rats $(78,125$, 126).

Epidemiological data indicate that the risk for CVD and heart failure increase with advancing age; however, sexual dimorphism exists in the chronological development of these risks $(55,102)$. The risk for CVD begins to increase at approximately the same age that flow-mediated vasodilation has been shown to decline in men (12). Women also exhibit this correlation; however, it occurs more than a decade later (12) and is associated with a decrease in arterial compliance in large arteries (59). Women experience cardioprotection until menopause, presumably due to estrogen, which then results in a sex-related delay of the expression of CVD (108). Some of the cardioprotective effects of estrogen include: a decrease in low-density lipoprotein, an increase in anti-platelet activity, enhanced levels of anti-oxidants, and the preservation of endothelium-mediated vasodilation $(64,67)$. After menopause, impairments in endothelium-dependent vasodilation of peripheral arteries in women are comparable to those in aged men $(12,108)$.

Estrogen can exert its effects in the vasculature by three different methods. Genomic activation of estrogen receptors is known as the classic pathway. When free estrogen diffuses into the cell, it binds to the nuclear estrogen receptors (ER) to exert 
conformational changes in the estrogen-ER complex which leads to its activation. This allows the complex to bind to specific DNA sequences known as estrogen-response elements to begin transcriptional activity (47). The nongenomic pathway begins with estrogen binding to the ER on the cell membrane which stimulates the activity of protein kinases to cause synthesis of target proteins. The protein kinases stimulated by the membrane ER can also exert transcriptional effects in the nucleus (47); however, nongenomic action through cell-surface ER receptors is mostly known for a rapid onset mechanism which causes vasodilation (47), primarily through nitric oxide synthase (NOS) (14). Lastly, a ligand-independent pathway involves growth factors which increase the activity of protein kinases which then phosphorylate the unbound ER in the cytoplasm to cause activation of transcriptional activity in the nucleus (39).

Estrogen has been shown to enhance function of the endothelium in a number of vascular beds $(15,121,123,124)$. Endothelium-dependent ACh-induced vasodilation in the peripheral vasculature is preserved or potentiated with chronic estrogen treatment in young male, ovariectomized (OVX) and sham-operated rats $(75,76,84,129)$. Estrogen also exerts cardioprotective effects by mediating ER-independent antioxidant action in the heart (104). Additionally, postmenopausal women display increases in total antioxidant capacity after undergoing 3 months of hormone replacement therapy (HRT) (22). In humans, impairment in endothelium-dependent vasodilation of peripheral conduit arteries is evident after menopause in females $(12,108)$; however, numerous studies have shown that chronic estrogen treatment enhances ACh- and/or flow-induced vasodilation compared to age-matched control males or females $(20,62,81,90)$. 
Recent reports indicate that estrogen exerts vasodilatory effects by binding to the ER-alpha to increase PI3-kinase activity, resulting in phosphorylation of PKB/Akt and endothelial nitric oxide synthase (eNOS) $(10,29,41,43,98)$. Acute estrogen treatment produces rapid vasodilation in numerous vascular beds $(10,29,41,95)$, and has been shown to preferentially enhance vasodilation in isolated coronary arteries from women versus men (15). Recently, chronic estrogen replacement was shown to improve endothelium-dependent vasodilation in coronary arteries of OVX mice (77). Thus, both acute and chronic estrogen treatment enhance nitric oxide (NO)-mediated endotheliumdependent vasodilation in young animals; however, more research is needed to examine how chronic estrogen treatment acts to prevent age-related declines in endothelial function in coronary arterioles of middle-aged and old animals. Realistically, a decline in circulating estrogen corresponds to these specific, but understudied, time points of the female lifespan.

The recent outcomes of the Women's Health Initiative (WHI) and Heart and Estrogen/Progestin Replacement Study (HERS), which found an increased risk for cardiovascular events in those women taking hormone-replacement therapy (HRT) compared to non-users $(49,87)$, has prompted investigations into the disparate findings between these randomized clinical trials and the overwhelming number of animal studies which have found a beneficial effect of estrogen-replacement (70). Discrepancies in the timing of hormone-replacement initiation, type and dose of estrogen/progesterone, and the age and health of women in clinical studies (82) warrant an optimized, more pertinent animal model that more closely resembles reproductive aging in women. Interestingly, the Nurse's Health Study which consisted of over 70,000 asymptomatic women found 
that the risk for major coronary events was lower in women taking hormone therapy compared to non-users (36-38). It is worthwhile to note that these women initiated hormone therapy in the perimenopausal period and were free from coronary heart disease at the time the study began; consequently, these factors may have contributed heavily to the beneficial results.

Therefore, the overall hypothesis of this proposal is that alterations in vascular reactivity that occur with age are gender-specific and may contribute to differences in the risk for CVD in aging men and women (111). An extended, more specific hypothesis is that the presence of estrogen contributes to the preservation or enhancement of endothelium-dependent vasoreactivity in coronary arterioles from females throughout their lifespan. Our knowledge of how age affects the coronary resistance vasculature is minimal, and information regarding the interaction between age and gender in the coronary microcirculation is virtually non-existent. Although the rate of aging is independent of gender, mechanisms that regulate the cardiovascular system during this time may differ dramatically between men and women. For that reason, the goals of this project were the following;

\section{To determine whether age and estrogen status alter endothelium-dependent} vasodilator responses in coronary resistance arterioles. Dilation to flow and Dea-NONOate was assessed in coronary arterioles from young (4 mo), middleaged (14 mo) and old (24 mo) female Fischer-344 rats which had been left intact, ovariectomized (OVX), or ovariectomized and estrogen-replaced (OVE). 
2. To determine whether gender and aging alters responsiveness of coronary resistance arterioles to a vasoconstrictor stimulus. Vasoconstrictor responses to endothelin were evaluated in intact and denuded coronary arterioles from young (4 months) and old (24 months) male and female Fischer rats. 


\section{CHAPTER II}

\section{ESTROGEN-REPLACEMENT IMPROVES WHILE AGING AND LOSS OF OVARIAN HORMONES IMPAIR FLOW-INDUCED VASODILATION IN CORONARY ARTERIOLES}

\section{OVERVIEW}

Epidemiological data indicate that the risk for cardiovascular disease (CVD) increases with advancing age; however, the age at which CVD risk increases significantly is delayed by more than a decade in women compared to men. This cardiac protection, which women experience until menopause, is presumably due to the presence of ovarian hormones, in particular estrogen. The purpose of this study was to determine how age and ovarian hormones affect flow-induced vasodilation in the coronary microcirculation. Coronary arterioles were isolated from young (6 mo), middle-aged (14 mo), and old (24 mo) control, ovariectomized (OVX) and ovariectomized + estrogen replaced (OVE) female Fischer-344 rats to assess vasodilation in response to increases in flow (5-60 $\mathrm{nl} / \mathrm{sec}$ ). L-NAME, a nitric oxide synthase (NOS) inhibitor, was used to assess the nitric oxide (NO) contribution to flow-induced dilation (FID). Advancing age impaired FID of coronary arterioles (Young: $50 \pm 4$ vs. Old: $34 \pm 6$; \% relaxation). Ovariectomy reduced FID in young females only; however, estrogen-replacement restored or improved FID in all age groups. Pretreatment with L-NAME in young control and all estrogen-replaced groups reduced FID, indicating that these dilator responses were mediated through NO. Increasing age caused an impairment of FID which corresponded to an age-related loss in NO-mediated dilation in the coronary microcirculation of female rats. FID in aged 
females appears to be impervious to OVX; however, estrogen-replacement improved FID by $\sim 160 \%$ versus old control and OVX.

\section{INTRODUCTION}

Epidemiological data indicate that the risk for cardiovascular disease (CVD) and heart failure increase with advancing age; however, sexual dimorphism exists in the chronological development of these risks $(55,102)$. Although the chronological rate of aging is independent of gender, mechanisms that regulate the cardiovascular system across the lifespan may differ dramatically between men and women. The risk for CVD in men begins to increase at approximately the same age that flow-mediated vasodilation begins to decline (12). Women also exhibit this age-related correlation in impaired vasodilation; however, it occurs more than a decade later at the age of menopause (12). The cardioprotection, which women experience until menopause, presumably is due to estrogen and results in a sex-related delay of the expression of CVD (108).

Chronic estrogen treatment has been shown to enhance endothelium function in a number of vascular beds $(76,81,91)$ through a well researched pathway involving the activation of AKT/PKB and subsequent phosphorylation of endothelial nitric oxide synthase (eNOS) $(8,29,43,98,99)$. Endothelium-dependent ACh-induced vasodilation in the peripheral vasculature is preserved or potentiated with chronic estrogen treatment in male, ovariectomized (OVX) and sham-operated rats $(75,76,84,129)$. In humans, impairment in endothelium-dependent vasodilation is evident after menopause in females $(12,108)$; however, numerous studies have shown that chronic estrogen treatment 
enhances ACh-and/or flow-induced vasodilation in large peripheral arteries of postmenopausal women $(20,62,90)$.

Recently, the Women's Health Initiative (WHI) (87) and Heart and Estrogen/Progestin Replacement Study (HERS) (49) found an increased risk for coronary heart disease and stroke in postmenopausal women taking hormone-replacement therapy (HRT) compared to non-users. This negative effect of HRT in postmenopausal women in the randomized clinical trials prompted investigations into the disparate results of animal studies which have found a beneficial effect of chronic estrogen treatment $(6,75,129)$. Even in humans, postmenopausal women have shown improved endothelium-dependent function in both small and large coronary arteries after short-term administration of estrogen $(31,40)$, which raises questions as to why long-term HRT increases the risk for coronary heart disease in women after menopause. Discrepancies in the timing of hormone-replacement initiation, type and dose of estrogen/progesterone, and the age and health of women in clinical studies (82) warrants an optimized, more pertinent animal model that more closely resembles reproductive aging in women. The present study utilizes a unique model, which allows identification of age-related microvascular changes while incorporating interventions such as the loss of ovarian hormones and/or estrogen replacement which can realistically occur later in the human lifespan.

The purpose of this study was to determine how advancing age, ovariectomy, and estrogen-replacement affect NO-mediated FID in the coronary microcirculation. Increasing age and lack of ovarian hormones were hypothesized to decrease FID in coronary arterioles. This study specifically investigated mechanisms that could underlie age- and estrogen-mediated changes in eNOS function. 


\section{METHODS}

Animals. Young (4 mo), middle-aged (12 mo) and old (22 mo) female Fischer344 rats were obtained from Harlan (Indianapolis, IN). At the time of arrival, rats were either sham-operated, ovariectomized (OVX), or ovariectomized + estrogen-replaced (OVE) and housed for 6 to 8 weeks post-operatively. All procedures were approved by the Institutional Animal Care and Use Committee at West Virginia University and conformed to the National Institutes of Health Guide for the Care and Use of Laboratory Animals (National Research Council, Washington D.C., Revised 1996). Rats were housed individually at $23^{\circ} \mathrm{C}$ and were maintained on a 12:12-h light-dark cycle. All rats were fed a phytoestrogen-free rat chow and water ad libitum. Prior to sacrifice, at least two complete estrous cycles were monitored in all female rats by daily vaginal smears. Subsequent analysis of the estrous cycle at time of sacrifice revealed no significant effect on vascular reactivity, which is consistent with large vessels (100). Plasma samples were collected at the time of sacrifice and stored at $-80^{\circ} \mathrm{C}$ until analysis. Plasma estrogen levels were measured in triplicate by radioimmunoassay (Estradiol, Ultra-Sensitive RIA Test, Diagnostic Systems).

Surgical Procedures. OVX were performed as described previously (85). OVE was performed simultaneous to the OVX procedure. Briefly, a scalpel was used to incise the top layer of skin in close proximity to the scapulae at a length of $1.0-1.5 \mathrm{~cm}$. The underlying skin was blunt dissected in order to subcutaneously implant two $0.05 \mathrm{mg}$ 17beta-estradiol 60-day slow release pellets (Innovative Research). The outer layer of skin was then sutured with absorbable suture (Maxon). 
Microvessel Preparation. Six to eight weeks after surgery, rats were anesthetized (Isoflurane $5 \% / \mathrm{O}_{2}$ balance) and euthanized by removal of the heart. Coronary arterioles from the left anterior descending artery (LAD) distribution were isolated and cannulated as described previously (97). Arterioles were cannulated on pipettes matched (within 1\%) for size and resistance, and pressurized at $60 \mathrm{cmH}_{2} \mathrm{O}$. Arterioles unable to hold pressure due to leaks were discarded. Those without leaks were warmed to $37^{\circ} \mathrm{C}$, and allowed to develop spontaneous tone.

Evaluation of vasodilator responses to intraluminal flow. Responses to flow were used to determine endothelial responsiveness to intraluminal shear stress. Once steady tone was achieved, arterioles were exposed to graded increases in intraluminal flow at constant intraluminal pressure by adjusting the height of the fluid reservoirs in equal but opposite directions, thereby creating a pressure difference across the arterioles without altering intraluminal pressure within the arterioles (54). Diameter measurements were determined in response to pressure differences of $2,4,10,20,40$, and $60 \mathrm{cmH}_{2} \mathrm{O}$, corresponding to physiologically significant flow rates from 5 to $60 \mathrm{nl} / \mathrm{sec}(78)$.

Responses to Dea-NONOate. Concentration-response relations to cumulative addition of the nitric oxide donor Dea-NONOate $\left(3 \times 10^{-9} \mathrm{M}-1 \times 10^{-4} \mathrm{M}\right)$ were determined in order to differentiate between alterations in endothelial signaling and sensitivity of the vascular smooth muscle to NO.

Maximal Diameter. At the conclusion of the experiment, the vessels were washed with $\mathrm{Ca}^{2+}$-free PSS every fifteen minutes for one hour to obtain maximal passive diameter at $60 \mathrm{cmH}_{2} \mathrm{O}$. 
Blockade of Nitric Oxide Synthase and Cyclooxygenase. In a second set of experiments, the contribution of nitric oxide to flow-induced vasodilation was reevaluated in the presence of $\mathrm{N}^{\mathrm{G}}$-nitro-L-arginine methyl ester (L-NAME; $1 \times 10^{-5} \mathrm{M}$ ), a nonspecific blocker of nitric oxide synthase (NOS). To determine the role of cyclooxygenase (COX) signaling, indomethacin $\left(1 \times 10^{-5} \mathrm{M}\right)$ or a combination of both inhibitors was applied to vessels during exposure to flow.

mRNA Expression. Arterioles were snap frozen and stored at $-80^{\circ} \mathrm{C}$ in $0.5 \mathrm{ml}$ microcentrifuge tubes. Arterioles were later pulverized in lysate buffer and total RNA was extracted using an aqueous and ethanol filter isolation method (RNAqueous Isolation Kit, Ambion). cDNA was made using the High Capacity cDNA Archive Kit (Applied Biosystems). Real-Time PCR was performed in triplicate, with two no-template control samples and two reverse transcriptase negative samples (GeneAmp 384 well Optical Reaction plates). Each reaction well contained the following: $7 \mathrm{ul} \mathrm{cDNA}, 10 \mathrm{ul}$ Universal PCR Master Mix, 1 ul 20XTarget Primers and Probe, 2 ul DEPC-treated water. Realtime PCR was performed with TaqMan ${ }^{\circledR}$ probes (Applied Biosystems) specific for rat Akt-1 (Applied Biosystems). Custom TaqMan(R) probes were designed from the published sequences for rat eNOS (eNOS primers at exon 8-9 junction: forward, GTG ACC CTC ACC GAT ACA ACA TAC; reverse, TGT CCG GGT GTC TAG ATC CAT). PCR was initiated by a 10 min step at $95^{\circ} \mathrm{C}$ followed by 45 two-step cycles of $15 \mathrm{~s}$ at $95^{\circ} \mathrm{C}$ and then $1 \mathrm{~min}$ at $60^{\circ} \mathrm{C}$. The fluorescent signal from the probe (FAM-labeled reporter dye; NFQ labeled-quencher dye) was measured by the ABI prism 7900HT Fast Real-Time PCR system. The number of cycles required for the fluorescence signal from each well to reach a fixed threshold is defined as the cycle threshold $(\mathrm{Ct})$. The 
fluorescence signals from $18 \mathrm{~S}$ mRNA served as controls for the differences in total cDNA loading in the wells. Levels of target sequence were quantified by calculating the difference between the $\mathrm{Ct}$ for the target sequence and coamplified 18S RNA $(\Delta \Delta \mathrm{Ct})$. One sample with the highest $\Delta \Delta \mathrm{Ct}$ value was chosen as a calibrator and assigned a Relative Quantification (RQ) value of 1.0. All other samples were quantified relative to the calibrator.

Protein Expression. Segments off of the LAD $\left(\leq 150 \mu \mathrm{m} \mathrm{D}_{\mathrm{M}} ; \sim 1000 \mu \mathrm{m}\right.$ in length) were dissected in cold PSS solution (-Albumin) $\left(4^{\circ} \mathrm{C}\right)$. Vessel pieces $(\mathrm{n}=4$ per tube) were snap frozen and stored at $-80^{\circ} \mathrm{C}$ until ready for use. After addition of $20 \mathrm{ul}$ Price-Laemmli lysis buffer, arterioles were solubilized by 3x 2-minute boil, vortex, and zip-spun. Thereafter, the arterioles were sonicated for 1 minute, and a final 2-minute boil, vortex, and zip-spin was performed. Protein determination was assessed using NanoOrange (Molecular Probes). Equal amounts of sample per lane were electrophoresed on $8 \%$ SDS-polyacrylamide gels and transferred to nitrocellulose membranes. Following blocking, membranes were incubated with primary antibodies for eNOS (1:1000) (BD Transduction Laboratories), p-AKT (1:500), p-eNOS (1:500), AKT (1:1000), or $\beta$-actin (1:1500) (Cell Signaling Technology) overnight $\left(4^{\circ} \mathrm{C}\right)$. Antibody binding was assessed by enhanced chemiluminescence (Super Signal, Pierce) following incubation with secondary anti-rabbit or anti-mouse antibodies as appropriate $(1 \mathrm{~h})$. Densitometric analysis of immunoblot films was performed using NIH ImageJ 1.38x Analysis Software (National Institutes of Health, Bethesda, MD). Data were normalized by expressing p-eNOS, p-AKT, eNOS, and AKT values relative to the $\beta$-actin loading control. p-eNOS and p-AKT were expressed relative to the $\beta$-actin loading control in 
order to distinguish between absolute differences in protein levels in the absence of possible age-related changes to either total eNOS or AKT.

Solutions and Chemicals. Albumin was purchased from USB Chemicals (Cleveland, OH). All other chemicals were purchased from Sigma Chemical (St. Louis, $\mathrm{MO})$.

Data Analysis. Data are expressed as means \pm standard error. Spontaneous tone was calculated as a percent constriction in relation to maximal diameter as determined by the following equation:

$$
\text { Spontaneous Tone }(\%)=\left[\left(\mathrm{D}_{\mathrm{M}}-\mathrm{D}_{\mathrm{T}}\right) / \mathrm{D}_{\mathrm{M}}\right] \times 100
$$

where $\mathrm{D}_{\mathrm{M}}$ is the maximal diameter recorded at $60 \mathrm{cmH}_{2} \mathrm{O}$ and $\mathrm{D}_{\mathrm{T}}$ is the steady-state baseline diameter recorded at the same pressure. The vasodilator responses to flow and Dea-NONOate are expressed as percent relaxation as calculated by the formula:

$$
\text { Relaxation } \%=\left[\left(D_{S}-D_{B}\right) /\left(D_{M}-D_{B}\right)\right] \times 100
$$

where $D_{S}$ is the arteriolar diameter at the respective stage, $D_{B}$ is the diameter recorded immediately prior to initiation of the flow- or concentration-diameter curves, and $\mathrm{D}_{\mathrm{M}}$ is the maximal diameter for the arteriole.

Flow-diameter and concentration-diameter curves were evaluated by repeated measures ANOVA in order to detect differences within (flow rate or concentration) and between (experimental groups) factors. A three-way ANOVA was performed to analyze the slope differences listed in Table 2.3. Pairwise comparisons were made by post-hoc analysis (Bonferroni's) when a significant main effect was found. One-way ANOVA was used to determine differences in BW, HW, HW/BW ratio, uterine weight, estradiol level, spontaneous tone, and maximal diameter. Significance was defined as $\mathrm{P} \leq 0.05$. 


\section{RESULTS}

\section{Animal Characteristics}

Middle-age and old control rats exhibited a greater body weight and heart weight than young control rats (Table 2.1). The ratio of heart weight to body weight was lower in middle-age and old control rats compared to young control rats (Table 2.1). Ovariectomy induced a significant increase in BW and decrease in $\mathrm{HW} / \mathrm{BW}$ ratio in young and middle-age females (Table 2.1). Estrogen-replacement caused a decrease in BW in middle-age and old females compared to age-matched control females, and the HW/BW ratio was increased in all age-groups vs. control (Table 2.1).Ovariectomy decreased uterine weight in all age groups compared to control (Table 2.1). Estrogenreplacement increased uterine weight compared to ovariectomized rats in all age groups (Table 2.1). Concentrations of estradiol were decreased in old females compared to young females (Table 2.1). Ovariectomy decreased estradiol concentrations in young rats (Table 2.1). Estrogen-replacement increased circulating estradiol levels significantly in young OVX rats (Table 2.1).

Vessel Characteristics

Maximal diameter was similar among arterioles from all female groups except young OVE rats, which exhibited a lower mean diameter (Table 2.2). Spontaneous tone achieved prior to any intervention was not altered by age or changes in estrogen status. Treatment with L-NAME increased tone to a similar degree in arterioles from all groups (Table 2.2). Indomethacin did not significantly alter tone in arterioles from any group compared to spontaneous tone prior to treatment (Table 2.2). L-NAME + indomethacin 
increased spontaneous tone to a similar degree in coronary arterioles from all groups except for young control and middle-aged OVX rats (Table 2.2).

Vasodilator responses to flow

Flow-induced dilation in coronary arterioles from old females was impaired compared to those from young females (Fig 2.1). FID in arterioles from middle-aged females was intermediate between young and old females.

OVX effect on flow-induced dilation

Coronary arterioles from young females exhibited a significant decline in flowinduced dilation after ovariectomy (Fig 2.2A), whereas dilation of coronary arterioles to flow in middle-age ovariectomized females was slightly, but not significantly decreased compared to control females of the same age (Fig 2.2B). Flow-induced dilation of coronary arterioles was unchanged in old females after ovariectomy (Fig 2.2C) OVE effect on flow-induced dilation

OVE significantly improved dilation of coronary arterioles to flow in all age groups compared to OVX (Fig 2.2). In old females, estrogen-replacement augmented flow-induced dilation to a level significantly greater than that of arterioles from either control or OVX rats (Fig 2.2C).

\section{NOS inhibition}

To determine whether NO contributed to flow-induced dilation in coronary arterioles, flow was performed in the presence of a nonspecific inhibitor of NOS (LNAME). In control females, only arterioles from young rats exhibited a decrease in flowinduced dilation after L-NAME treatment (Fig 2.3A), indicating a loss of NO contribution to flow with advancing age. Flow-induced dilation in OVX females of all 
ages was impervious to prior incubation with L-NAME (Fig 2.4). Conversely, blockade with L-NAME abolished dilation to flow in all OVE females, indicating a reliance on NO-dependent vasodilation after estrogen replacement, regardless of age (Fig 2.5).

\section{COX inhibition}

To demonstrate the limited effect of COX inhibition on flow-induced dilation in females, the average slope of the dilation to flow before and after treatment with indomethacin is outlined in Table 2.3 and shown in Appendix A-I. Indomethacin treatment increased the average slope of the flow-dilation curve in arterioles from old females, indicating that a COX-dependent constrictor pathway limits flow-induced dilation in advanced age (Table 2.2). In contrast, flow-induced dilation after treatment with indomethacin in arterioles from old OVE females was reduced as indicated by a decrease in the average slope of the flow-dilation curve compared to control conditions (Table 2.3). In all other females, indomethacin treatment did not alter flow-induced dilation of coronary arterioles (Table 2.3).

Combined NOS and COX inhibition

In all groups, combined NOS and COX inhibition on FID in coronary arterioles was similar to NOS inhibition alone (Appendix A-I).

\section{Vasodilator responses to DEA-NONOate}

To determine whether the age-related impairment of vasodilation in coronary arterioles was due to a decrease in smooth muscle responsiveness to NO, vasodilation to DEA-NONOate was measured. DEA-NONOate elicited similar dilation in coronary arterioles from young, middle-aged, and old females (Fig 2.6A). In addition, neither OVX nor OVE altered dilation of coronary arterioles to DEA-NONOate compared to 
dilation of arterioles from age-matched control rats (Fig 2.6 B,C,D). Coronary arterioles from middle-aged OVE rats exhibited greater dilation to DEA-NONOate than those from MA OVX rats $\left(\mathrm{IC}_{50}\right.$ : MA OVX $\left.=2.31 \times 10^{-6} \mathrm{M}, \mathrm{MA} \mathrm{OVE}=7.01 \times 10^{-7} \mathrm{M} ; \mathrm{P} \leq 0.05\right)$.

\section{AKT and eNOS mRNA levels}

In coronary arterioles from control females, AKT mRNA expression declined with age (Fig 2.7A). OVX decreased (vs. control) while OVE increased (vs. OVX) AKT mRNA in coronary arterioles from both young and middle-age females (Fig 2.7A). In coronary arterioles from middle-aged and old OVX rats, estrogen-replacement increased AKT mRNA expression to levels greater than those of arterioles from age-matched control rats (Fig 2.7A).

Similar to AKT mRNA, advancing age also caused a decrease in eNOS mRNA in coronary arterioles from middle-age and old control females compared to arterioles from young females; however, OVX did not alter eNOS mRNA in any age group (Fig 2.7B). OVE upregulated eNOS mRNA in both young and middle-age females compared to control and OVX (Fig 2.7B). Surprisingly, OVE did not alter eNOS mRNA in coronary arterioles from old rats (Fig 2.7B).

p-eNOS, p-AKT, eNOS, and AKT protein levels

Basal p-AKT was undectable in coronary arterioles from all groups. Total AKT was similar in coronary arterioles from all groups (Fig 2.8 and Appendix N-Q). There was a $40 \%$ age-related decline in basal p-eNOS protein with advancing age (YC: $0.63 \pm 0.10$, OC: $0.38 \pm 0.05$; arbitrary units) (Fig 2.8A); however, no age-related differences were found in total eNOS protein levels (Fig 2.8A and Appendix J). Coronary arterioles from young females exhibited no changes in p-eNOS or total eNOS 
protein after OVX or OVE (Fig 2.8B and Appendix K). There was a 93\% increase in peNOS after OVE treatment in middle-age females (MC: $0.54 \pm 0.08$, M OVE: $1.04 \pm 0.25$; arbitrary units) (Fig 2.8C), but no changes were found in total eNOS after treatment (Fig 2.8C and Appendix L). After OVE, coronary arterioles from old females exhibited a $49 \%$ increase in p-eNOS (OC: $0.35 \pm 0.04$, O OVE: $0.52 \pm 0.02$; arbitrary units) and a $67 \%$ increase in total eNOS protein (OC: $0.48 \pm 0.05$, O OVE: $0.80 \pm 0.10$; arbitrary units) (Fig 2.8D). 


\begin{tabular}{|c|c|c|c|c|c|c|c|c|c|}
\hline & $\begin{array}{l}\text { Young } \\
\text { Control }\end{array}$ & $\begin{array}{c}\text { MA } \\
\text { Control } \\
\end{array}$ & $\begin{array}{c}\text { Old } \\
\text { Control }\end{array}$ & $\begin{array}{c}\text { Young } \\
\text { ovx } \\
\end{array}$ & $\begin{array}{l}\text { MA } \\
\text { OVX } \\
\end{array}$ & $\begin{array}{l}\text { Old } \\
\text { ovx } \\
\end{array}$ & $\begin{array}{c}\text { Young } \\
\text { OVE } \\
\end{array}$ & $\begin{array}{l}\text { MA } \\
\text { OVE } \\
\end{array}$ & $\begin{array}{l}\text { Old } \\
\text { OVE } \\
\end{array}$ \\
\hline \multicolumn{10}{|l|}{ Body } \\
\hline Weight (BW) (g) & $210 \pm 3$ & $262 \pm 4^{*}$ & $304 \pm 4^{*}$ & $241 \pm 5^{\dagger}$ & $278 \pm 6^{\dagger}$ & $298 \pm 5$ & $212 \pm 5^{\#}$ & $249 \pm 5^{\# \#}$ & $281 \pm 7^{\ddagger}$ \\
\hline (n) & (24) & (17) & (20) & (17) & (21) & (13) & (12) & (14) & (9) \\
\hline \multicolumn{10}{|l|}{ Heart } \\
\hline Weight (HW) (mg) & $595 \pm 11$ & $699 \pm 14^{*}$ & $760 \pm 17^{*}$ & $623 \pm 12$ & $700 \pm 16$ & $761 \pm 18$ & $622 \pm 21$ & $744 \pm 15^{\ddagger}$ & $854 \pm 43^{\ddagger \#}$ \\
\hline HW/BW (mg/g) & $2.83 \pm 0.03$ & $2.67 \pm 0.04^{*}$ & $2.52 \pm 0.06^{*}$ & $2.60 \pm 0.04^{\dagger}$ & $2.52 \pm 0.04^{\dagger}$ & $2.56 \pm 0.06$ & $2.97 \pm 0.07$ & $2.99 \pm 0.04$ &  \\
\hline Uterine Weight (mg) & $507 \pm 41$ & $628 \pm 32^{*}$ & $537 \pm 49$ & $118 \pm 13^{\dagger}$ & $194 \pm 20^{\dagger}$ & $292 \pm 48^{\dagger}$ & $233 \pm 22^{\# \#}$ & $491 \pm 33^{\ddagger \#}$ & $721 \pm 64^{\#}$ \\
\hline Estradiol (pg/ml) & $66 \pm 16$ & & $<20$ & $<20$ & & & $40 \pm 8$ & & \\
\hline
\end{tabular}

Table 2.1. Animal characteristics of young, middle-aged, and old control, OVX, and OVE rats. Values are means \pm SE. * Indicates significant age-related difference vs. young control, $\dagger$ Indicates significant OVX effect vs. age-matched control, $\$$ Indicates significant OVE effect vs. age-matched control, \# Indicates significant OVE effect vs. age-matched OVX $(\mathrm{P} \leq 0.05)$ 


\begin{tabular}{|c|c|c|c|c|c|c|c|c|c|}
\hline & $\begin{array}{l}\text { Young } \\
\text { Control }\end{array}$ & $\begin{array}{c}\text { MA } \\
\text { Control }\end{array}$ & $\begin{array}{c}\text { Old } \\
\text { Control }\end{array}$ & $\begin{array}{c}\text { Young } \\
\text { ovx }\end{array}$ & $\begin{array}{l}\text { MA } \\
\text { ovx }\end{array}$ & $\begin{array}{l}\text { Old } \\
\text { ovx }\end{array}$ & $\begin{array}{c}\text { Young } \\
\text { OVE }\end{array}$ & $\begin{array}{l}\text { MA } \\
\text { OVE }\end{array}$ & $\begin{array}{l}\text { Old } \\
\text { OVE }\end{array}$ \\
\hline \multicolumn{10}{|l|}{ Maximum } \\
\hline Diameter $(\mu \mathrm{m})$ & $\begin{array}{c}136 \pm 4 \\
(31)\end{array}$ & $\begin{array}{c}138 \pm 5 \\
(23)\end{array}$ & $\begin{array}{c}143 \pm 5 \\
(33)\end{array}$ & $\begin{array}{c}131 \pm 5 \\
(28)\end{array}$ & $\begin{array}{c}142 \pm 5 \\
(31)\end{array}$ & $\begin{array}{c}144 \pm 5 \\
(31)\end{array}$ & $\begin{array}{c}123 \pm 5^{\ddagger} \\
(23)\end{array}$ & $\begin{array}{c}141 \pm 4 \\
(29)\end{array}$ & $\begin{array}{r}136 \pm 5 \\
(29)\end{array}$ \\
\hline Spontaneous Tone (\%) & $\begin{array}{c}43 \pm 3 \\
(31)\end{array}$ & $\begin{array}{l}49 \pm 3 \\
(23)\end{array}$ & $\begin{array}{c}46 \pm 3 \\
(33)\end{array}$ & $\begin{array}{c}49 \pm 4 \\
(28)\end{array}$ & $\begin{array}{l}51 \pm 3 \\
(31)\end{array}$ & $\begin{array}{l}52 \pm 3 \\
(31)\end{array}$ & $\begin{array}{c}45 \pm 5 \\
(23)\end{array}$ & $\begin{array}{l}52 \pm 3 \\
(29)\end{array}$ & $\begin{array}{r}45 \pm 3 \\
(29)\end{array}$ \\
\hline Pre-LNAME & $\begin{array}{l}42 \pm 3 \\
(14)\end{array}$ & $\begin{array}{l}49 \pm 4 \\
(14)\end{array}$ & $\begin{array}{r}46 \pm 4 \\
(14)\end{array}$ & $\begin{array}{l}49 \pm 4 \\
(16)\end{array}$ & $\begin{array}{c}45 \pm 3 \\
(15)\end{array}$ & $\begin{array}{c}50 \pm 4 \\
(13)\end{array}$ & $\begin{array}{r}40 \pm 6 \\
(14)\end{array}$ & $\begin{array}{l}50 \pm 3 \\
(16)\end{array}$ & $\begin{array}{r}42 \pm 4 \\
(15)\end{array}$ \\
\hline Post- LNAME & $\begin{array}{r}54 \pm 5 \\
(14)\end{array}$ & $\begin{array}{r}59 \pm 3 \\
(14)\end{array}$ & $\begin{array}{r}67 \pm 5 \\
(14)\end{array}$ & $\begin{array}{r}62 \pm 7 \\
(16)\end{array}$ & $\begin{array}{r}70 \pm 4 \\
(15)\end{array}$ & $\begin{array}{r}68 \pm 3 \\
(13)\end{array}$ & $\begin{array}{r}60 \pm 8 \\
(14)\end{array}$ & $\begin{array}{r}63 \pm 5 \\
(16)\end{array}$ & $\begin{array}{r}63 \pm 6 \\
(15)\end{array}$ \\
\hline Pre-INDO & $\begin{array}{l}39 \pm 5 \\
(5)\end{array}$ & $\begin{array}{c}37 \pm 3 \\
(5)\end{array}$ & $\begin{array}{c}34 \pm 6 \\
(8)\end{array}$ & $\begin{array}{c}30 \pm 5 \\
(8)\end{array}$ & $\begin{array}{c}42 \pm 4 \\
(8)\end{array}$ & $\begin{array}{c}34 \pm 7 \\
(5)\end{array}$ & $\begin{array}{l}30 \pm 3 \\
(6)\end{array}$ & $\begin{array}{c}46 \pm 5 \\
(7)\end{array}$ & $\begin{array}{c}37 \pm 4 \\
(9)\end{array}$ \\
\hline Post- INDO & $\begin{array}{c}36 \pm 4 \\
(5)\end{array}$ & $\begin{array}{l}35 \pm 3 \\
(5)\end{array}$ & $\begin{array}{c}39 \pm 5 \\
(8)\end{array}$ & $\begin{array}{c}39 \pm 5 \\
(8)\end{array}$ & $\begin{array}{c}48 \pm 5 \\
(8)\end{array}$ & $\begin{array}{c}43 \pm 4 \\
(5)\end{array}$ & $\begin{array}{c}33 \pm 4 \\
(6)\end{array}$ & $\begin{array}{c}53 \pm 4 \\
(7)\end{array}$ & $\begin{array}{c}46 \pm 6 \\
(9)\end{array}$ \\
\hline Pre-LNAME + INDO & $\begin{array}{c}39 \pm 5 \\
(5)\end{array}$ & $\begin{array}{c}39 \pm 3 \\
(6)\end{array}$ & $\begin{array}{c}34 \pm 7 \\
(7)\end{array}$ & $\begin{array}{c}30 \pm 5 \\
(8)\end{array}$ & $\begin{array}{c}41 \pm 5 \\
(7)\end{array}$ & $\begin{array}{c}35 \pm 4 \\
(7)\end{array}$ & $\begin{array}{c}31 \pm 3 \\
(7)\end{array}$ & $\begin{array}{c}46 \pm 6 \\
(6)\end{array}$ & $\begin{array}{c}36 \pm 4 \\
(11)\end{array}$ \\
\hline $\begin{array}{c}\text { Post- LNAME + } \\
\text { INDO } \\
\end{array}$ & $\begin{array}{c}50 \pm 5 \\
(5)\end{array}$ & $\begin{array}{r}52 \pm 5 \\
(6) \\
\end{array}$ & $\begin{array}{r}60 \pm 6 \\
(7) \\
\end{array}$ & $\begin{array}{r}62 \pm 9 \\
(8) \\
\end{array}$ & $\begin{array}{c}53 \pm 9 \\
(7) \\
\end{array}$ & $\begin{array}{r}68 \pm 3 \\
(7) \\
\end{array}$ & $\begin{array}{r}53 \pm 5 \\
(7) \\
\end{array}$ & $\begin{array}{r}74 \pm 4 \\
(6) \\
\end{array}$ & $\begin{array}{r}65 \pm 6 \\
(11) \\
\end{array}$ \\
\hline
\end{tabular}

Table 2.2. Vessel characteristics of isolated coronary arterioles in young, middle-aged, and old control, OVX, and OVE rats. Values are means \pm SE. * Indicates significant age-related difference vs. young control, $\uparrow$ Indicates significant OVX effect vs. age-matched control, $₫$ Indicates significant OVE effect vs. age-matched control, \# Indicates significant OVE effect vs. age-matched OVX, Indicates significant inhibitor effect vs. control $(\mathrm{P} \leq 0.05)$. 


\begin{tabular}{|c|c|c|c|c|c|c|c|c|c|}
\hline & $\begin{array}{c}\text { Young } \\
\text { Control } \\
\end{array}$ & $\begin{array}{c}\text { MA } \\
\text { Control } \\
\end{array}$ & $\begin{array}{c}\text { Old } \\
\text { Control } \\
\end{array}$ & $\begin{array}{c}\text { Young } \\
\text { ovX } \\
\end{array}$ & $\begin{array}{c}\text { MA } \\
\text { OVX } \\
\end{array}$ & $\begin{array}{l}\text { Old } \\
\text { ovx } \\
\end{array}$ & $\begin{array}{c}\text { Young } \\
\text { OVE } \\
\end{array}$ & $\begin{array}{c}\text { MA } \\
\text { OVE } \\
\end{array}$ & $\begin{array}{l}\text { Old } \\
\text { OvE } \\
\end{array}$ \\
\hline \multicolumn{10}{|l|}{ Mean Slope $(\beta)$ of } \\
\hline Flow-induced Dilation & $\begin{array}{c}0.98 \pm 0.09 \\
(14)\end{array}$ & $\begin{array}{c}0.92 \pm 0.20 \\
(14)\end{array}$ & $\begin{array}{c}0.62 \pm 0.12 \\
(14)\end{array}$ & $\begin{array}{c}0.62 \pm 0.08 \\
(16)\end{array}$ & $\begin{array}{c}0.53 \pm 0.13 \\
(15)\end{array}$ & $\begin{array}{c}0.62 \pm 0.21 \\
(13)\end{array}$ & $\begin{array}{c}0.94 \pm 0.07 \\
(14)\end{array}$ & $\begin{array}{c}1.02 \pm 0.12 \\
(16)\end{array}$ & $\begin{array}{c}1.19 \pm 0.12 \\
(15)\end{array}$ \\
\hline Post-INDO & $\begin{array}{c}0.87 \pm 0.16 \\
(5)\end{array}$ & $\begin{array}{c}0.60 \pm 0.13 \\
(5)\end{array}$ & $\begin{array}{c}1.08 \pm 0.30 \\
(8)\end{array}$ & $\begin{array}{c}0.67 \pm 0.14 \\
(8)\end{array}$ & $\begin{array}{c}0.58 \pm 0.18 \\
(8)\end{array}$ & $\begin{array}{c}0.79 \pm 0.13 \\
(5)\end{array}$ & $\begin{array}{c}0.96 \pm 0.23 \\
(6)\end{array}$ & $\begin{array}{c}0.77 \pm 0.24 \\
(7)\end{array}$ & $\begin{array}{c}0.65 \pm 0.12 \\
(9)\end{array}$ \\
\hline
\end{tabular}

Table 2.3. Mean slope $(\beta)$ of flow-induced dilation before and after treatment with indomethacin $\left(1 \times 10^{-5} \mathrm{M}\right)$, a COX inhibitor, in isolated coronary arterioles in young, middle-aged, and old control, OVX, and OVE rats. Values are means \pm SE. Indicates significant inhibitor effect vs. control $(\mathrm{P} \leq 0.05)$. 


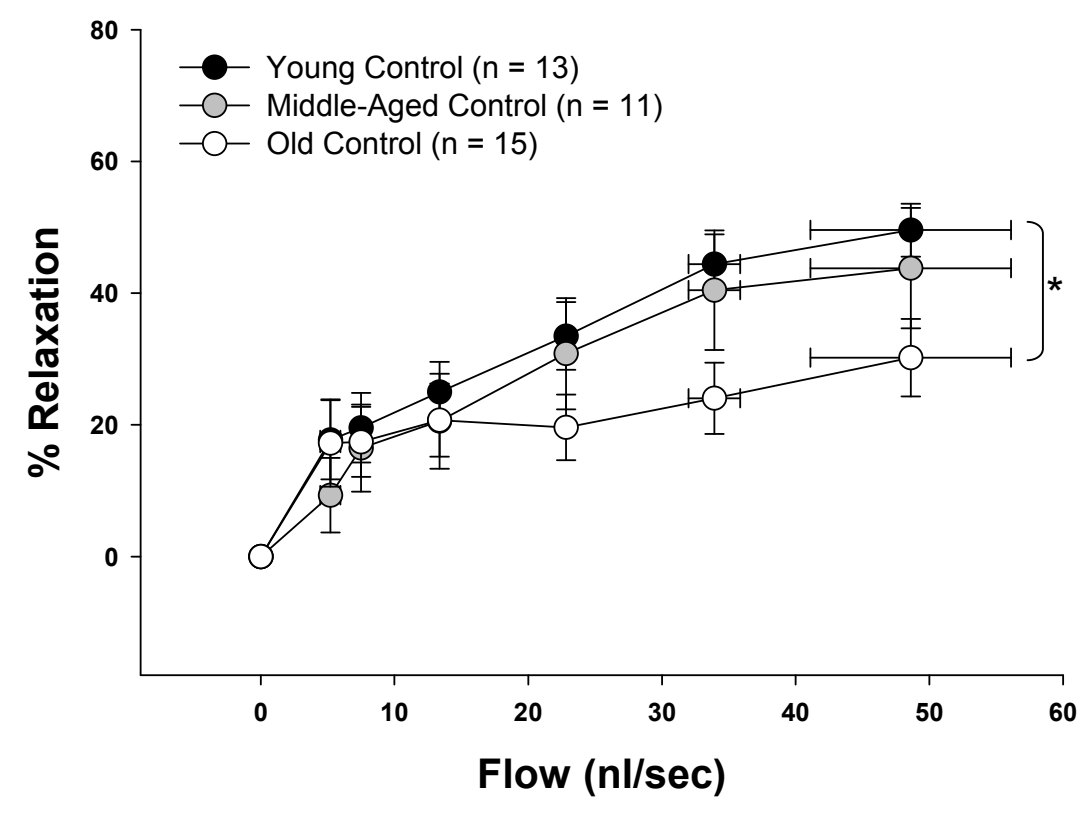

Figure 2.1. Flow-induced dilation in young, middle-aged and old control females. Old females have less dilation to flow than young females. Values are means \pm SE. * Indicates significant age-related difference vs. young control $(\mathrm{P} \leq 0.05)$. 
A



B

Flow (nl/sec)

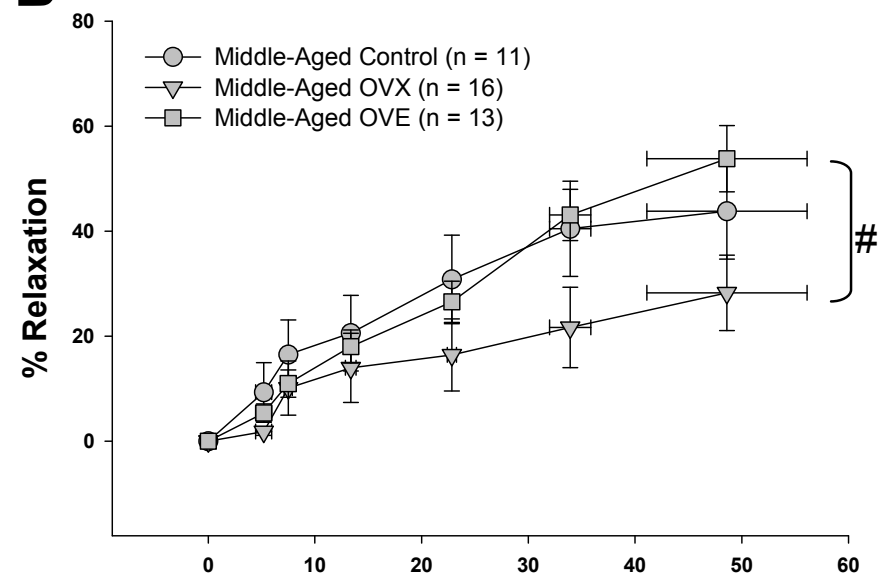

$\mathbf{C}_{80}$

Flow (nl/sec)

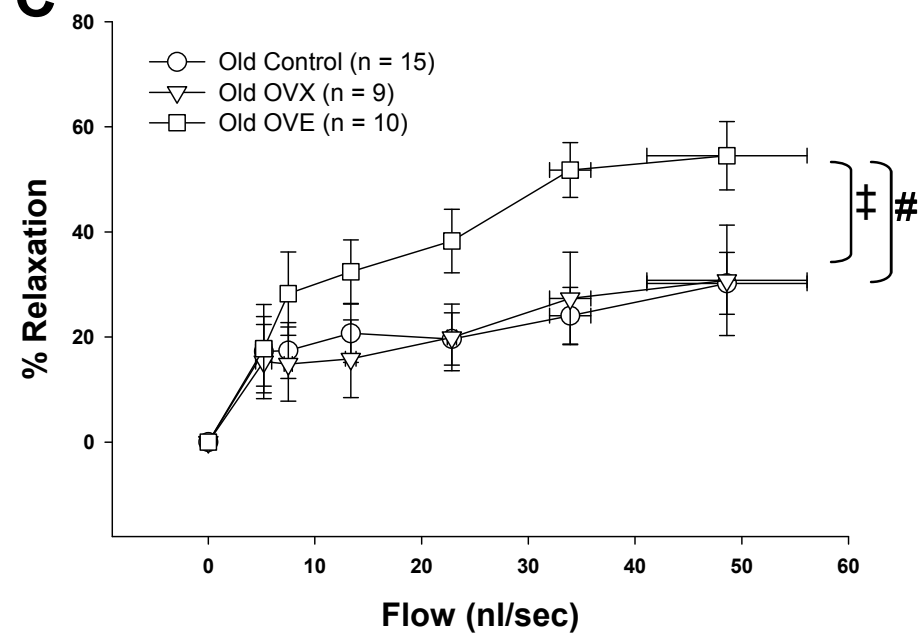

Figure 2.2. A) Flow-induced dilation is decreased after OVX in young females, but restored to control levels after OVE. B) OVX does not decrease FID in middle-age females, but OVE increases FID compared to OVX. C) OVE increases FID in old females. Values are means \pm SE. † Indicates significant OVX effect vs. control, $¥$ Indicates significant OVE effect vs. control, \# Indicates significant OVE effect vs. $\operatorname{OVX}(\mathrm{P} \leq 0.05)$. 

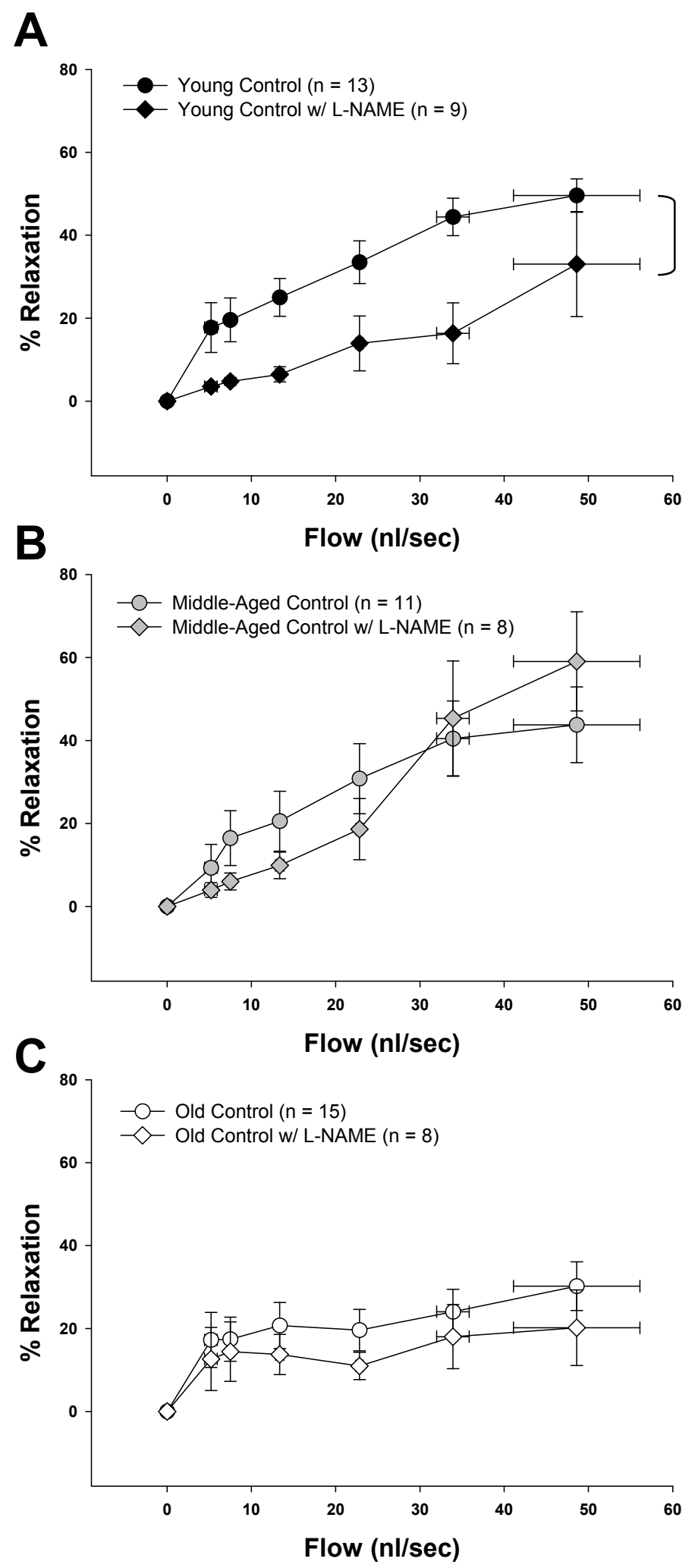

Figure 2.3. Flow-induced dilation in the presence and absence of L-NAME $\left(1 \times 10^{-5} \mathrm{M}\right)$, a NOS inhibitor, in young, middle-age, and old control females. FID in young females is reduced after pretreatment with LNAME (A). Values are means \pm SE. Indicates significant inhibitor effect vs. control $(P \leq 0.05)$. 
A
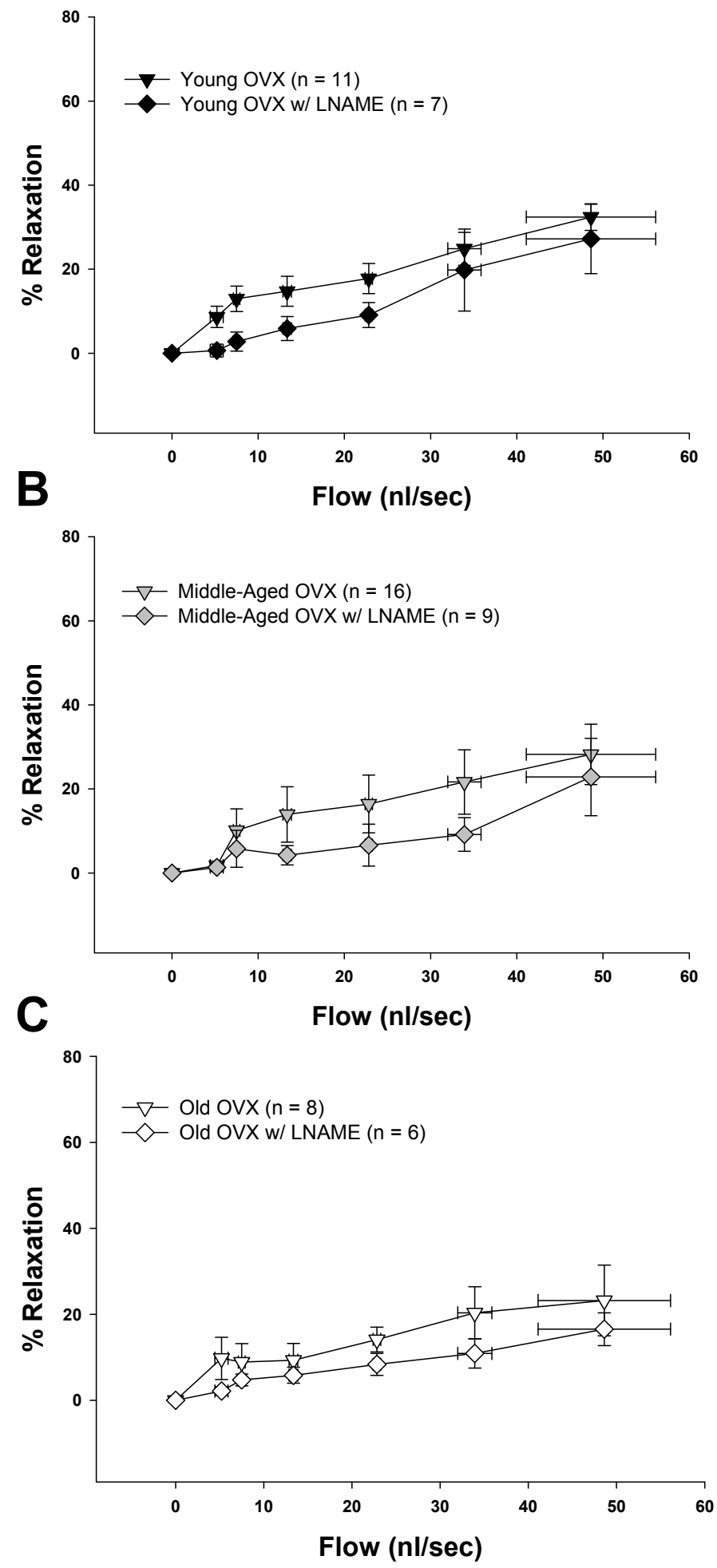

Figure 2.4. Flow-induced dilation in the presence and absence of L-NAME $\left(1 \times 10^{-5} \mathrm{M}\right)$, a NOS inhibitor, in young, middle-age, and old OVX females. L-NAME did not alter FID in OVX females. Values are means $\pm \mathrm{SE}$. 



Figure 2.5. Flow-induced dilation in the presence and absence of L-NAME $\left(1 \times 10^{-5} \mathrm{M}\right)$, a NOS inhibitor, in young, middle-age, and old OVE females. FID is decreased after pretreatment with L-NAME in all age groups. Values are means $\pm \mathrm{SE}$. Indicates significant inhibitor effect vs. control $(\mathrm{P} \leq 0.05)$. 
A

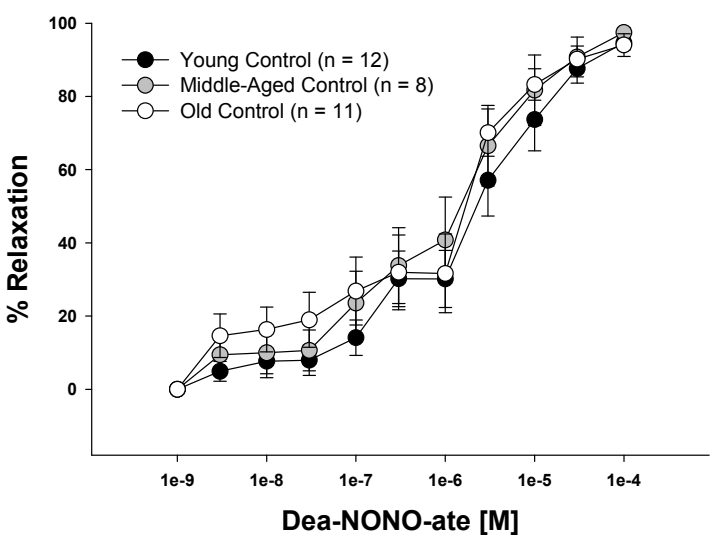

C

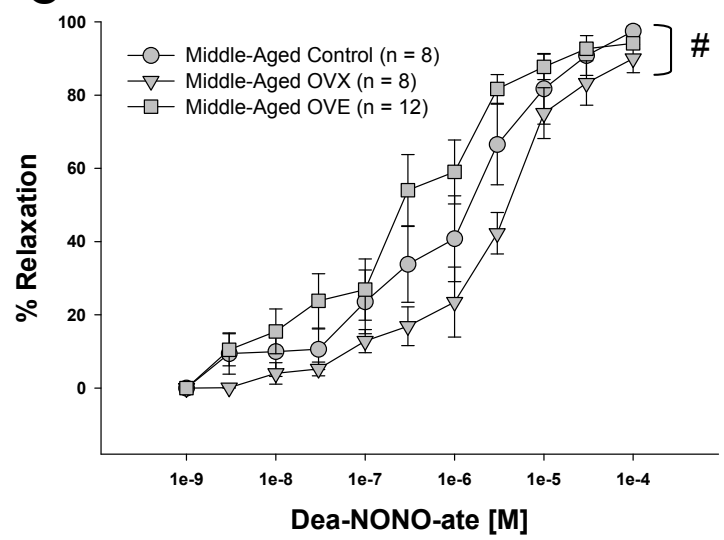

B

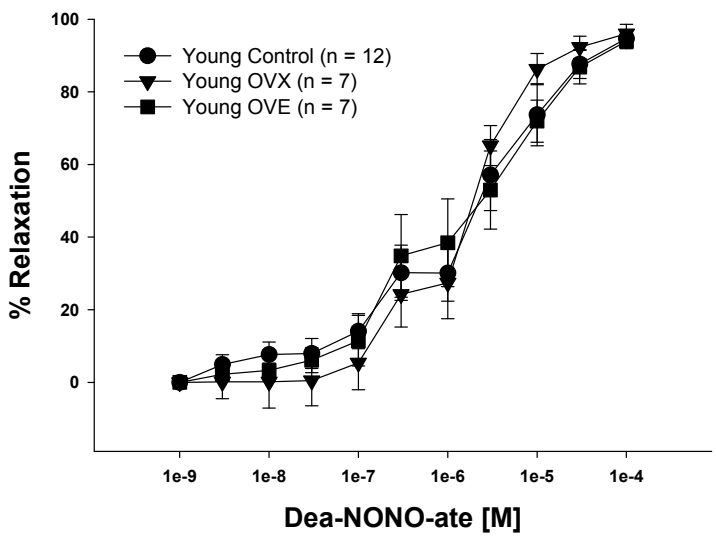

D

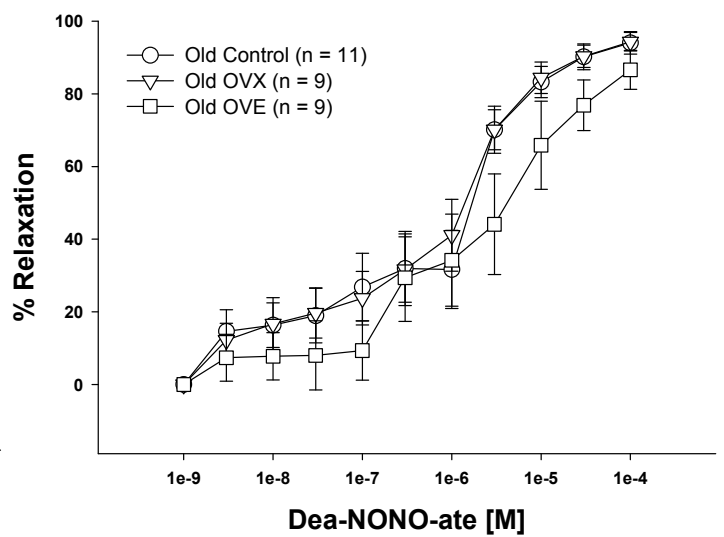

Figure 2.6. Concentration-response curves to Dea-NONOate, an exogenous NO donor. Dilation to DeaNONOate did not change with advancing age or after treatment compared to control. Sensitivity $\left(\mathrm{IC}_{50}\right.$ values) for Dea-NONOate in coronary arterioles from middle-aged OVE was greater than those from


significant OVE effect vs. age-matched OVX $(\mathrm{P} \leq 0.05)$. 

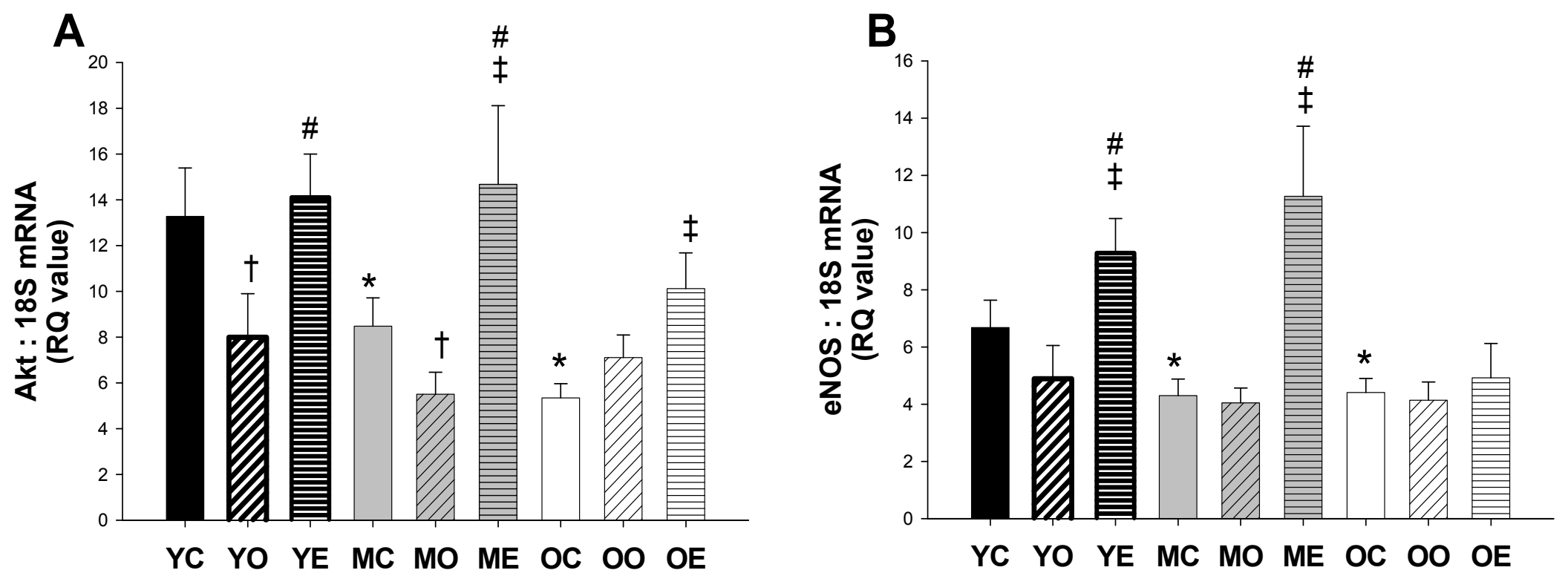

Figure 2.7. mRNA RQ values for AKT (A) and eNOS (B) for all female groups ( $\mathrm{n} \geq 8$ per group). Values are means \pm SE. * Indicates significant age-related difference vs. young control, $\uparrow$ Indicates significant OVX effect vs. age-matched control, $\downarrow$ Indicates significant OVE effect vs. age-matched control, \# Indicates significant OVE effect vs. age-matched OVX $(\mathrm{P} \leq 0.05)$. 



Figure 2.8. Western blot analysis of $\mathrm{p}$-eNOS relative to $\beta$-actin loading control (bar graphs). There was an age-dependent decrease in p-eNOS protein (A) (YC: 8, MC: 4, OC: 7; $\mathrm{n}$ values). There was no OVX or OVE effect in p-eNOS in arterioles from young females (B) (YC: 14, YO: 6, YE: 6; $n$ values). Middle-age females exhibited more p-eNOS protein after OVE compared to control (C) (MC: 6, MO: 7, ME: 5; n values). Old females upregulated p-eNOS and total eNOS protein after OVE (D) (OC: 10, OO: 3, OE: 3; n values). Values are means \pm SE. * Indicates significant age-related difference vs. young control, $\$$ Indicates significant OVE effect vs. age-matched control $(\mathrm{P} \leq 0.05)$. 


\section{DISCUSSION}

Although there are numerous reports in the literature detailing the beneficial influence of OVE on the vasculature in young animals $(10,29,41,95)$, there are relatively few studies examining the influence of exogenous estrogen on the aged vasculature. Therefore, the foremost finding of this study is that FID in coronary arterioles of old OVE female rats was improved above FID in arterioles from old control and old OVX rats (Fig 2.2C), indicating a favorable coronary microvascular response to estrogen-replacement following ovariectomy in this aged population. This encouraging improvement in endothelial function is accompanied by an increase in both p-eNOS and total eNOS protein after estrogen-replacement (Fig 2.8D). Congruent with the hypothesis, coronary arterioles from young females exhibited a decline in FID after ovariectomy (Fig 2.2A) and OVE restored dilation to flow in coronary arterioles from young and middle-age female rats compared to OVX alone (Fig 2.2 A,B). As hypothesized, FID was decreased with advancing age in control females due to the loss of NO-mediated dilation (Fig 2.1, 2.3).

The novelty of this study is the examination of the coronary microcirculation throughout the lifespan of female rats and the investigation of the effects of estrogen status in young, middle-aged, and old rats. Endothelium-dependent vasodilation has been shown to be inversely correlated with aging in large epicardial coronary arteries (27). Vasodilation of coronary arteries in response to noradrenaline (79), adenosine (45), and testosterone (28) declines with age. Additionally, impaired endothelium-dependent vasodilation of septal arteries $(\sim 200 \mu \mathrm{m})$ in middle-aged male rats has been reported (18). However, much of the current literature regarding aging effects in the coronary 
vasculature is confined to studies of larger resistance arteries from males. The present study illustrates an age-related impairment in endothelium-dependent dilation in coronary arterioles from female rats (Fig 2.1), which is associated with a decrease in p-eNOS protein (Fig 2.8a) and the loss of NO-dependent dilation (Fig 2.3). These findings extend previous studies showing that FID in females decreases with advancing age in brachial arteries $(12,83)$ and mesenteric arteries (4).

In the present study, young females were the only age group where OVX decreased FID (Fig 2.2A). Blockade with L-NAME indicated that OVX reduced FID through a loss of NO-mediated signaling (Fig 2.4A). In the cerebral microcirculation, OVX has been shown to completely abolish endothelium-dependent dilation due to upregulation of caveolin-1, a negative regulator of eNOS (84). In all OVX groups, FID was NOS- and COX-independent as indicated by the lack of L-NAME and/or indomethacin effect (Fig 2.4 and Appendix D-F). Xu, et al. (127) found that cerebral arterioles from OVX rats lose NO contribution compared to those from control rats, but are more sensitive to a $\mathrm{K}_{\mathrm{Ca}}{ }^{2+}$ channel blocker, suggesting a conversion to hyperpolarizing factor dependency in the absence of estrogen. Golding and Kepler have shown that in cerebral arteries of control female rats, endothelial derived hyperpolarizing factor (EDHF)-mediated dilations are negligible but can be enhanced after OVX (32). Therefore, it seems plausible that a conversion from NO-dependency to EDHF dependency of FID occurs after OVX in all age groups, especially young females.

Estrogen-replacement after OVX enhanced FID of coronary arterioles from all age groups (Fig 2.2). OVE restored FID in coronary arterioles from young and middleaged females to the level seen in control (Fig 2.2 A,B), while in old females OVE 
increased FID of coronary arterioles to a level significantly greater than responses in coronary arterioles from old control and OVX (Fig 2.2C). This enhanced FID in coronary arterioles from old OVE females corresponds to increases in NO-signaling, $\mathrm{p}$ eNOS and total eNOS protein (Fig 2.8D). Restoration of NO-dependent dilation to control levels after OVE has been observed previously in cerebral arteries (84), and was primarily mediated through an increase in eNOS protein expression. Similarly, in the coronary microcirculation of guinea pigs, estrogen-replacement following OVX increased dilator sensitivity through an enhancement of endothelium-dependent NO production (112). Additionally, multiple human studies have shown that HRT in postmenopausal women improves FID in peripheral conduit arteries $(20,62,90)$. These data now show that estrogen supplementation also improves NO-mediated vasodilation in the coronary resistance vasculature even at an advanced age.

The age-related impairment of FID in old females is presumably due to a loss of NO-mediated dilation, as demonstrated by an absence of L-NAME inhibition of FID (Fig 2.3 A,C). Previous work in mesenteric arterioles has demonstrated that advancing age causes a decrease in shear stress-induced production of p-eNOS and NO (105). In this study, the loss of NO-mediated FID with advancing age coincides with an apparent increase in COX-dependent vasoconstriction, indicated by a significant increase in FID after pretreatment with indomethacin of coronary arterioles from old females (Appendix C). Stewart et al. have established that a decline in circulating estrogen (6) and advancing age (103) enhances prostaglandin $\mathrm{H}$ synthase (PGHS)-2-dependent vasoconstriction in mesenteric arteries while simultaneously decreasing NO-dependent vasodilation. Likewise, an increase in circulating estrogen improved vasodilation in aged 
rats by decreasing both PGHS-dependent constriction in mesenteric arteries (6) and EDHF-mediated dilation in cerebral arteries (32). In the present study, inhibition with indomethacin caused a reduction in the slope of FID in arterioles from old OVE females compared to pretreatment FID in old OVE rats (Table 2.3). This indicates that estrogenreplacement reduced COX-dependent vasoconstriction which was present in FID of coronary arterioles from old control females. In the present study, L-NAME abolished FID in coronary arterioles from OVE rats in all age groups (Fig 2.5) indicating substantial NO-dependence of FID in estrogen-replaced rats. The precise mechanism whereby estrogen improves NO-mediated vasodilation has not been demonstrated but may be due to estrogen effects on eNOS expression or mechanisms that regulate eNOS function, such as the PI3-kinase/AKT pathway $(10,29,43)$.

In endothelial cells, acute administration of estrogen causes phosphorylation of AKT within one minute, followed closely by phosphorylation of eNOS (29). In the present study, in the absence of acute stimulation, p-AKT was undetectable in pooled coronary arteriole samples. Bhuiyan, et al. found no changes in p-AKT or total AKT protein after OVX in left ventricular tissue from female Wistar rats (8). Although there are reports in the literature detailing molecular evidence that $\mathrm{AKT}$ is responsive to the presence of estrogen $(29,48,99)$, these studies utilize an acute exposure to estrogen rather than the chronic estrogen treatment used in the present study. Although it would seem reasonable that chronic administration of estrogen would lead to an increase in mRNA and protein of AKT, while a lack of circulating estrogen (with advancing age or with OVX) would reduce AKT expression, these results indicate that chronic alterations in circulating estrogen levels alter AKT mRNA expression rather than AKT protein 
expression. Thus, the current findings suggest estradiol regulation of NO-signaling occurs at other sites of regulation, possibly through effects on eNOS expression (Fig 2.8A) or upstream signaling at the level of the cell membrane.

Whereas AKT has been largely unstudied after chronic estrogen replacement, there is an abundance of reports illustrating both the presence $(69,84,86,93)$ and absence $(8,52,80)$ of estrogenic modulation of eNOS expression in various vascular beds. The present data show that the removal of estrogen (OVX) does not alter eNOS mRNA expression. In contrast, eNOS mRNA is upregulated by OVE in coronary arterioles from young and middle-aged females (Fig 2.7B). OVE has also been reported to increase eNOS mRNA in the thoracic aorta (86). Similar to findings reported in cerebral microvessels (52), mesenteric arteries (80), and left ventricular tissue (8); neither OVX nor OVE altered total eNOS protein in coronary arterioles from young and middleaged rats (Appendix K,L). In contrast to the present results obtained in young rats, both p-eNOS and total eNOS protein were increased in arterioles from old females after estrogen-replacement (compared to control, Fig 2.8D). However, OVX and OVE did not alter eNOS mRNA expression in coronary arterioles from old rats. Numerous posttranslational modifications can influence the activity of eNOS, and may contribute to the increase in NO-mediated vasodilation in middle-aged and old females, including decreases in ubiquitination, methylation, or receptor degradation after estrogenreplacement. Considered together, these data suggest that the age-related decrease in peNOS protein (Fig 2.8A) and NO-mediated dilation to flow that occurs in coronary arterioles can be ameloriated by upregulation of post-translational mechanisms that enhance function of eNOS protein in old female rats supplemented with estrogen. 
Collectively, a beneficial effect of estrogen-replacement following ovariectomy was demonstrated on endothelial function in the coronary microcirculation of aged female rats; however, recent randomized, placebo-controlled trials in older women receiving HRT have not shown any benefit in either primary prevention or secondary prevention of coronary heart disease and/or myocardial infarction $(49,87)$. One logical explanation for the discrepancy between studies may be attributed to differences in the timing of initiation of estrogen-replacement following ovariectomy (or hysterectomy/menopause in women). The WHI initiated HRT at a mean age of 63 years, placing the women at least 10 years after menopause (87). There are many factors that could influence the overall outcome of HRT in the decade gap between menopause and initiation of HRT, including changes in body composition, overall activity levels, and the health of the vasculature that were not taken into account in the clinical trials. These factors may have contributed to the increased risk for cardiovascular events in postmenopausal women even after HRT. The Nurse's Health Study, an observational study consisting of 70,000 asymptomatic women, initiated HRT in the perimenopausal period and showed a lower incidence of cardiovascular events and all-cause mortality compared to non-HRT-users (36-38). In fact, a recent reanalysis of the WHI results found that women who initiated HRT closer to menopause tended to have a lower risk of overall coronary heart disease (88). Perhaps the simultaneous estrogen-replacement and ovariectomy in the present study resulted in the maintenance of healthy endothelial function, mitigating the progression of deleterious cardiovascular alterations, such as atherosclerosis, known to flourish in postmenopausal women (35). Animal studies (117), the Nurse's Health Study (36-38), and the Cardiovascular Health Study (46) all suggest 
that favorable effects of estrogen may be limited to those in whom atherosclerosis has not yet developed.

In the present study, increases in body weight with advancing age and after ovariectomy were associated with a decrease in endothelium-dependent vasodilation in coronary arterioles. Previous research in brachial arteries have shown that in an overweight population, endothelial function is most impaired in the highest tertile of body weight compared to the lowest (5), while postmenopausal women with higher visceral body fat exhibit lower flow-mediated velocity when compared with leaner subjects (65). In the coronary circulation, an increase in body weight has been shown to be independently associated with abnormal coronary circulatory function that progresses from impairment in vascular vasomotion in overweight individuals to an impairment of total vasodilator capacity in obese individuals (92). Fulop et al. recently found that in normotensive subjects, dilations to bradykinin and sodium nitroprusside, an NO donor, were both decreased in isolated pressurized coronary arterioles from obese humans (30). Therefore, a possible interaction may exist between a change in body fat mass and endothelial function that may be superimposed upon alterations that occur with advancing age and hormonal state.

The major finding from this study is that estrogen-replacement following ovariectomy restores or enhances FID in coronary arterioles from all ages of female Fischer-344 rats. Not only does estrogen-replacement improve FID in coronary arterioles from aged females compared to arterioles from old control and OVX females, it also eliminates age-related impairments in FID in coronary arterioles by upregulating the contribution of NO to dilation, p-eNOS and total eNOS protein. These observations are 
in stark contradiction to the recent negative outcomes of both the WHI and HERS studies but answers key questions as to the functional integrity of the coronary microvasculature in aged females after estrogen-replacement. Taken together, the present study suggests that the timing of HRT and the overall health of the vasculature are vital components to positive effects of estrogen-replacement in postmenopausal women. 


\section{CHAPTER III}

\section{AGING AND GENDER EFFECTS ON VASOCONSTRICTION TO ENDOTHELIN IN CORONARY ARTERIOLES}

\section{OVERVIEW}

Epidemiological data indicate that the risk for CVD and heart failure increase with advancing age; however, sexual dimorphism affects the chronological development of these risks (12). Coronary blood flow is regulated by the release of a combination of vasodilators and vasoconstrictors, and altered coronary vasoconstrictor responses in both males and females may contribute to the decline in coronary function and increased risk for CVD that occurs with advancing age. Coronary arterioles were isolated from young (6 mo) and old (24 mo) male and female Fischer-344 rats to assess vasoconstriction responses to endothelin $(\mathrm{ET})\left(1 \times 10^{-11}\right.$ to $\left.3 \times 10^{-8} \mathrm{M}\right)$. An ETa receptor inhibitor, BQ123 $\left(1 \times 10^{-6} \mathrm{M}\right)$, or an ETb receptor inhibitor, BQ788 $\left(3 \times 10^{-8} \mathrm{M}\right)$, was used to assess specific receptor contribution to ET-induced vasoconstriction in intact and endothelium-denuded arterioles. In coronary arterioles from males, ET-induced vasoconstriction declined with advancing age and was accompanied by a decrease in ETa receptor mRNA and protein expression. In contrast, ET-induced vasoconstriction increased in coronary arterioles from females with advancing age and neither ETa nor ETb receptor mRNA or protein expression changed with age. Thus, aging-induced alterations in responsiveness of the coronary resistance vasculature are gender-specific, possibly contributing to the sexual dimorphism in the risk of CVD with advancing age. 


\section{INTRODUCTION}

Overwhelming evidence demonstrates that gender plays an important role in the development of cardiovascular disease with advancing age. Specifically, endothelial dysfunction occurs more than a decade later in women compared to men. Recent data $(60,61)$ suggest that endothelium-dependent dilation declines with age in coronary arterioles from both males and female rats; however, the underlying mechanisms that contribute to the decline in endothelial function are gender-specific. In contrast, little is known with regard to sex-specific adaptations of vasoconstrictor responses that occur in the coronary vasculature with advancing age. Previous work indicates that endothelial modulation of vasoconstrictor responses increased with age in coronary arterioles from male rats (96); however, because estrogen exerts a potent vasodilatory influence in the vasculature, it seems plausible that a decline in circulating estrogen that occurs with old age in females might lead to an increase in vasoconstrictor responses.

Advancing age causes a decrease in cardiac function (3) and reduces maximal and submaximal coronary blood flow in aged rats (42) and humans (19). Endothelin (ET) is a 21-amino acid vasoconstrictor peptide that is released from the coronary vasculature in response to a stimulus from cardiac myocytes (71), causing a potent and long-lasting coronary vasoconstriction (118). Others have previously shown an altered response to ET in the aorta (7) and in large coronary arteries (51) with advancing age. Furthermore, a decrease in ET-induced vasoconstriction in coronary resistance arterioles occurred with advancing age in male rats (97); however, it remains to be determined whether age alters ET-mediated responses of coronary arterioles from females as it does in males. 
ET has been shown to be involved in determining basal coronary arteriolar tone, and a reduction in its presence contributes to regulation of coronary blood flow during increased metabolism (72). The long-lasting vasoconstriction caused by ET can redirect coronary blood flow in order to promote subendocardial perfusion, and has been proposed to prevent excessive back flow from the coronary circulation (71). Endothelin mediates its effects via two distinct G-coupled protein receptor subtypes. ETa receptors are the major subtype of receptors involved in the vasoconstrictor response to ET and are localized on the vascular smooth muscle (VSM) cell (66). ETb receptors located on the endothelial cell mediate vasodilation through the release of relaxing factors, but can exert vasoconstriction through ETb receptors located on the smooth muscle (66). Therefore, the net effect of endothelin depends on the relative distribution and density of each specific subtype of receptor. This laboratory has previously shown that advancing age decreases vasoconstriction to ET in coronary arterioles from males (97); however, the precise mechanisms of the reduced responsiveness to ET seen in coronary arterioles have not been identified, nor has the effect of age on responsiveness to ET been investigated in females. The effects of age on ET signaling through specific receptor subtypes have not been investigated in the coronary circulation of males or females. Therefore, the goals of this study were to 1) determine whether age-induced alterations in vasoconstrictor responses of coronary arterioles are gender specific, and 2) determine the effects of age on signaling through ETa and ETb receptors in coronary arterioles from male and female rats.

\section{METHODS}


Animals

Young $(6 \mathrm{mo} ; \mathrm{n}=54)$ and old $(24 \mathrm{mo} ; \mathrm{n}=48)$ male and young $(\mathrm{n}=35)$ and old $(\mathrm{n}=34)$ female Fischer-344 rats were obtained from Harlan (Indianapolis, IN). All procedures were approved by the Institutional Animal Care and Use Committee at West Virginia University and conformed to the National Institutes of Health Guide for the Care and Use of Laboratory Animals (National Research Council, Washington D.C., Revised 1996). Rats were housed individually at $23^{\circ} \mathrm{C}$ and were maintained on a 12:12h light-dark cycle. All rats were fed standard rat chow and water ad libitum.

\section{Microvessel Preparation}

Rats were anesthetized (isoflurane $5 \% / \mathrm{O}_{2}$ balance) and euthanized by removal of the heart. The heart was rinsed and placed in cold $\left(4^{\circ} \mathrm{C}\right)$ physiological saline solution (PSS) containing $145.0 \mathrm{mM} \mathrm{NaCl}, 4.7 \mathrm{mM} \mathrm{KCl}, 2.0 \mathrm{mM} \mathrm{CaCl}_{2}, 1.17 \mathrm{mM} \mathrm{MgSO}_{4}, 1.2$ $\mathrm{mM} \mathrm{NaH} \mathrm{PO}_{4}, 5.0 \mathrm{mM}$ glucose, $2.0 \mathrm{mM}$ pyruvate, $0.02 \mathrm{mM}$ EDTA, $3.0 \mathrm{mM}$ MOPS buffer, and $1 \mathrm{~g} / 100 \mathrm{ml} \mathrm{BSA}, \mathrm{pH}$ 7.4. Resistance vessels $(<150 \mu \mathrm{m})$ from the left anterior descending artery distribution were dissected free under a dissection microscope (Olympus SVH10) and removed from the surrounding cardiac tissue. The arterioles were transferred to a Lucite chamber containing PSS equilibrated with room air. The ends of the arteriole were cannulated with a micropipette and secured with nylon suture The chamber containing the cannulated arteriole was then place on an inverted microscope (Olympus IX70) equipped with a video camera and micrometer (Panasonic BP310; Texas A\&M Cardiovascular Research Institute) to measure the intraluminal diameter. The coronary arterioles were then pressurized at $60 \mathrm{~cm} \mathrm{H}_{2} \mathrm{O}$ with two hydrostatic columns. 
Arterioles unable to hold pressure due to leaks or branches were discarded. Those without leaks were warmed to $37^{\circ} \mathrm{C}$ and allowed to develop spontaneous tone.

\section{Responses to Endothelin}

To determine whether aging alters sensitivity and/or maximal responses to ET, a concentration-response curve to ET was generated. Changes in diameter were measured in response to cumulative additions of ET $\left(1 \times 10^{-11} \mathrm{M}-3 \times 10^{-8} \mathrm{M} ; 5\right.$-minute stages $)$ to the vessel bath.

\section{ET Receptor Blockade}

To determine the contribution of ET receptor subtypes in the age-related alteration of ET-mediated constriction, the ET concentration-response was evaluated in the presence of either a specific $\mathrm{ET}_{\mathrm{A}}$ receptor $\left(\mathrm{BQ}-123,1 \times 10^{-6} \mathrm{M}\right)$ or $\mathrm{ET}_{\mathrm{B}}$ receptor $(\mathrm{BQ}-$ $\left.788,3 \times 10^{-8} \mathrm{M}\right)$ antagonist (73).

\section{Removal of the Endothelium}

To determine the role of the endothelium in modulating ET-induced vasoconstriction, the endothelium was removed, and the above experiments were repeated. The endothelium was denuded by passing approximately $12 \mathrm{cc}$ of air through the vessel lumen. Lack of vasodilation to $3 \times 10^{-4} \mathrm{M}$ ACh confirmed removal of the endothelium.

\section{Passive Pressure Responses}

In order to determine maximal diameter and passive responses to increasing pressure, the solution in the bath and pressure lines was replaced with calcium-free PSS containing 2.0 mM EDTA. Arterioles were washed every 15 minutes and allowed to completely relax at $60 \mathrm{~cm} \mathrm{H} \mathrm{H}_{2} \mathrm{O}$ for 45 minutes. Maximal diameter at $60 \mathrm{~cm} \mathrm{H}_{2} \mathrm{O}$ was 
recorded, and then the passive pressure response was determined by lowering the pressure reservoirs to $0 \mathrm{~cm} \mathrm{H}_{2} \mathrm{O}$, and recording diameters as pressure was increased incrementally by $15 \mathrm{~cm} \mathrm{H}_{2} \mathrm{O}$ to $135 \mathrm{~cm} \mathrm{H}_{2} \mathrm{O}$. This procedure was performed in arterioles from females only, as a similar experiment has already been performed in arterioles from males (97).

\section{Determination of ETa and ETb receptor mRNA}

Arterioles were snap frozen and stored at $-80^{\circ} \mathrm{C}$ in $0.5 \mathrm{ml}$ microcentrifuge tubes. Arterioles were later pulverized in lysate buffer and total RNA was extracted using an aqueous and ethanol filter isolation method (RNAqueous Isolation Kit, Ambion). cDNA was made using the High Capacity CDNA Archive Kit (Applied Biosystems). RealTime PCR was performed in triplicate, with two no-template control samples and two reverse transcriptase negative samples, using GeneAmp 384 well Optical Reaction plates. Each reaction well contained the following: $7 \mathrm{ul}$ cDNA, $10 \mathrm{ul}$ Universal PCR Master Mix, 1 ul 20XTarget Primers and Probe, 2 ul DEPC-treated water. Real-time PCR was performed with TaqMan ${ }^{\circledR}$ probes (Applied Biosystems) designed for rat ETa receptor and ETb receptor. PCR was initiated by a 10 min step at $95^{\circ} \mathrm{C}$ followed by 45 two-step cycles of $15 \mathrm{~s}$ at $95^{\circ} \mathrm{C}$ and then $1 \mathrm{~min}$ at $60^{\circ} \mathrm{C}$. The fluorescent signal from the probe (FAM-labeled reporter dye; NFQ labeled-quencher dye) was measured by the ABI prism 7900HT Fast Real-Time PCR system. The number of cycles required for the fluorescence signal from each well to reach a fixed threshold is defined as the cycle threshold $(\mathrm{Ct})$. The fluorescence signals from 18S mRNA served as controls for the differences in total cDNA loading in the wells. Levels of target sequence were quantified by calculating the difference between the $\mathrm{Ct}$ for the target sequence and coamplified $18 \mathrm{~S}$ 
RNA $(\Delta \Delta \mathrm{Ct})$. One sample with the highest $\Delta \Delta \mathrm{Ct}$ value was chosen as a calibrator and assigned a Relative Quantification (RQ) value of 1.0. All other samples were quantified relative to the calibrator.

\section{Determination of ETa and ETb receptor protein}

Coronary arterioles $(n=4 /$ rat $)$ were immediately snap frozen and stored at $-80^{\circ} \mathrm{C}$ until ready for use. After addition of 15 ul lysis buffer, arterioles were solubilized and protein content was assessed by NanoOrange assay (Molecular Probes). Five $\mu \mathrm{g}$ of protein from each sample was electrophoresed on 10\% SDS-polyacrylamide gels and transferred to polyvinylidene difluoride (PVDF) membranes. Following blocking (6\% nonfat dry milk), membranes were incubated with primary antibodies overnight at $4{ }^{\circ} \mathrm{C}$ (ETa (1:1000) or ETb (1:1000) (Sigma-Aldrich)). After washing, membranes were incubated with the appropriate horseradish peroxidase-conjugated species-specific antiIgG (1 h). Peroxidase activity was detected by enhanced chemiluminescence (Super Signal West Femto, Pierce). Densitometric analysis of immunoblot films was performed using NIH ImageJ 1.38x Analysis Software (National Institutes of Health, Bethesda, MD). Equal loading was confirmed by Sypro Ruby staining for total protein.

\section{Solutions and Drugs}

Albumin was purchased from USB Chemicals (Cleveland, OH). All other chemicals were purchased from Sigma Chemical (St. Louis, MO).

\section{Data Analysis}

Data are expressed as means \pm standard error.

$$
\text { Spontaneous Tone }(\%)=\left[\left(\mathrm{D}_{\mathrm{M}}-\mathrm{D}_{\mathrm{T}}\right) / \mathrm{D}_{\mathrm{M}}\right] \times 100
$$


where $\mathrm{D}_{M}$ is the maximal diameter recorded at $60 \mathrm{cmH}_{2} \mathrm{O}$ and $\mathrm{D}_{T}$ is the steady-state baseline diameter recorded at the same pressure. Constriction to ET was expressed by the following equation:

$$
\text { Constriction }(\%)=\left[\left(\mathrm{D}_{\mathrm{b}}-\mathrm{D}_{\mathrm{s}}\right) / \mathrm{ID}_{\mathrm{b}}\right] \times 100
$$

where $\mathrm{D}_{\mathrm{b}}$ is the baseline diameter immediately prior to addition of the first dose of vasoconstrictor agonist, and $\mathrm{D}_{\mathrm{s}}$ is the steady state diameter measured after addition of each dose. Arteriolar distensibility was calculated by the following equation:

Distensibility $(\%$ change in arteriolar diameter $/ \mathrm{mmHg})=\left[\Delta \mathrm{ID} /\left(\mathrm{D}_{\mathrm{s}} \times \Delta \mathrm{P}_{\mathrm{IL}}\right)\right] \times 100$ where $\Delta$ ID represents the change in internal arteriolar diameter for each incremental change in intraluminal pressure $\left(\Delta \mathrm{P}_{\mathrm{IL}}\right)$, and $\mathrm{D}_{\mathrm{s}}$ is the steady state diameter measured after increasing intraluminal pressure.

Concentration-diameter curves were evaluated by repeated measures ANOVA in order to detect differences within and between factors. Pairwise comparisons were made by post-hoc analysis (Bonferroni) when a significant main effect was found. One-way ANOVA was used for comparisons of animal and vessel characteristics. Significance was set at $(\mathrm{P} \leq 0.05)$.

\section{RESULTS}

\section{Animal Characteristics}

Old male and female rats had a higher body weight and heart weight than young male and female rats (Table 3.1). Heart weight to body weight ratio was increased with age in males, but decreased in females (Table 3.1).

Vessel Characteristics 
Maximal diameter of coronary arterioles was increased in old males compared to young male (Table 3.1). Spontaneous tone was greater in arterioles from young males compared to arterioles from young females (Table 3.1). Arterioles from old females developed greater spontaneous tone after denudation compared to young females (Table 3.1). BQ-123 did not alter spontaneous tone in any group. BQ-788 decreased spontaneous tone only in arterioles from young males (Table 3.1).

Response to ET

Old age altered the vasoconstriction to ET in coronary arterioles from both male and female rats (Fig 3.1). As shown previously, ET-induced vasoconstriction was impaired in arterioles from old males compared to those from young males (Fig 3.1A). In contrast, age increased vasoconstriction to ET in arterioles from female rats (Fig 3.1B). In young rats, vasoconstriction to ET did not differ between arterioles from males and females; however, ET-induced vasoconstriction was greater in arterioles from old female rats compared to arterioles from old male rats (Fig 3.1). Following denudation, agerelated differences were abolished in coronary arterioles from male rats (Fig 3.2A), but remained in coronary arterioles from female rats (Fig 3.2B).

Contribution of ETa receptor

There were no age-related differences in ET-induced vasoconstriction in intact arterioles after pretreatment with BQ-788, an ETb receptor inhibitor, in either males or females (Fig 3.3). Following denudation, ET-induced vasoconstriction in the presence of BQ-788 remained greater in arterioles from young males compared to those from old males (Fig 3.4A). Vasoconstriction to ET in the presence of BQ-788 in denuded coronary arterioles from old females was greater than those from young females (Fig 
3.4B). These data indicate that ETa receptor-mediated vasoconstriction is altered with age in both males and females.

Contribution of ETb receptor

There were no age-related differences in ET-induced vasoconstriction in intact arterioles after pretreatment with BQ-123, an ETa receptor inhibitor, in either males or females (Fig 3.3). Likewise, in denuded artetioles from both males and females, agerelated differences to ET-induced vasoconstriction were abolished by pretreatment with BQ-123 (Fig 3.4). These data indicate that ETb receptor-mediated vasoconstriction is preserved with age in males and females.

Passive Pressure Response

To determine whether structural changes contributed to age-induced changes in ET-mediated vasoconstriction, passive distensibility curves were determined in coronary arterioles from young and old female rats. There were no age-related differences between the passive responses to increasing pressure in arterioles from young and old female rats (Fig 3.5). Previous data demonstrated that age did not alter the passive pressure-diameter relationship in arterioles from male rats (97).

ETa and ETb receptor $m R N A$ expression

Both ETa and ETb receptor mRNA expression was decreased in arterioles from old males compared to arterioles from young males (Fig 3.6 A,B). However, neither ETa or ETb receptor mRNA expression was altered with age in coronary arterioles from females (Fig 3.6 C,D).

ETa and ETb receptor protein expression 
ETa receptor protein was decreased in arterioles from old males compared to arterioles from young males (Fig 3.7A). ETb receptor protein was increased in coronary arterioles from old males compared to arterioles from young males (Fig 3.7B). There were no age-related differences in ETa or ETb receptor protein in coronary arterioles from females (Fig 3.7 C,D). 


\begin{tabular}{ccccc} 
& $\begin{array}{c}\text { Young } \\
\text { Male }\end{array}$ & $\begin{array}{c}\text { Old } \\
\text { Male }\end{array}$ & $\begin{array}{c}\text { Young } \\
\text { Female }\end{array}$ & $\begin{array}{c}\text { Old } \\
\text { Female }\end{array}$ \\
\hline \hline $\begin{array}{c}\text { Animal Characteristics } \\
\text { Body Weight (g) } \\
\text { (n) }\end{array}$ & $330 \pm 6$ & $394 \pm 5^{*}$ & $205 \pm 2$ & $298 \pm 3^{*}$ \\
& $(54)$ & $(48)$ & $(35)$ & $(34)$ \\
Heart Weight (mg) & $1,007 \pm 18$ & $1,385 \pm 23^{*}$ & $582 \pm 9$ & $774 \pm 12^{*}$ \\
HW/BW (mg/g) & $3.06 \pm 0.04$ & $3.54 \pm 0.08^{*}$ & $2.83 \pm 0.03$ & $2.62 \pm 0.05^{*}$ \\
& & & & \\
Vessel Characteristics & $120 \pm 3$ & $131 \pm 4^{*}$ & $124 \pm 3$ & $126 \pm 4$ \\
Maximal Diameter $(\mu \mathrm{m})$ & $(50)$ & $(54)$ & $(50)$ & $(49)$ \\
& & & & \\
Spontaneous Tone (\%) & $34 \pm 2$ & $29 \pm 2$ & $28 \pm 2 \dagger$ & $31 \pm 3$ \\
Endothelium Intact & $(9)$ & $(10)$ & $(10)$ & $(8)$ \\
Denuded & $32 \pm 6$ & $28 \pm 6$ & $24 \pm 5$ & $40 \pm 6^{*}$ \\
Post BQ123 & $(6)$ & $(9)$ & $(7)$ & $(11)$ \\
Post BQ788 & $33 \pm 6$ & $23 \pm 4$ & $35 \pm 5$ & $29 \pm 4$ \\
& $(15)$ & $(15)$ & $(15)$ & $(14)$ \\
& $26 \pm 4 \ddagger$ & $24 \pm 4$ & $23 \pm 5$ & $24 \pm 6$ \\
\hline \hline
\end{tabular}

Table 3.1. Animal and vessel characteristics of young and old male and female rats. Values are means \pm SE. * Indicates significant age-effect, $\uparrow$ Indicates significant age-matched gender difference, $†$ Indicates significant treatment effect compared to spontaneous tone $(\mathrm{P} \leq 0.05)$. 

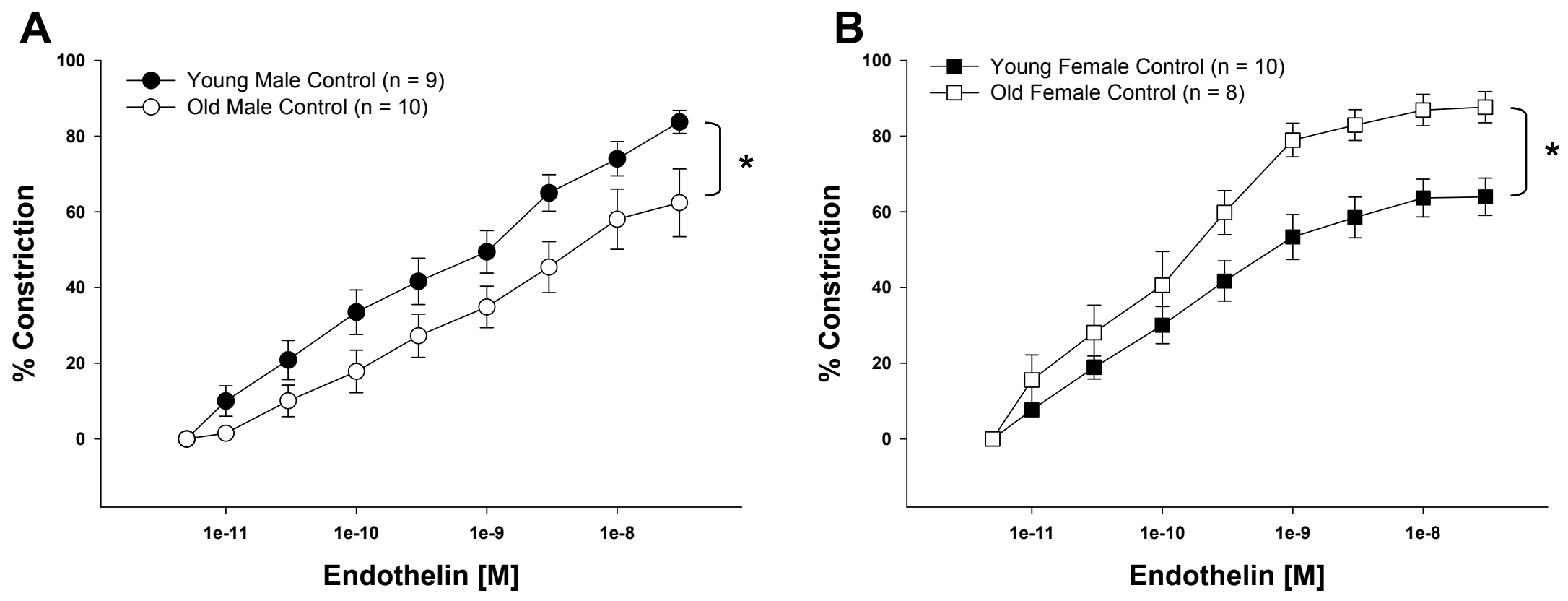

Figure 3.1. Vasoconstriction to ET in coronary arterioles from young and old males (A) and females (B). ET-induced vasoconstriction was decreased with advancing age in coronary arterioles from males (A), but increased in coronary arterioles from aged females (B). Values are means \pm SE. * Indicates significant age-related difference vs. young control, $(\mathrm{P} \leq 0.05)$. 
A



B

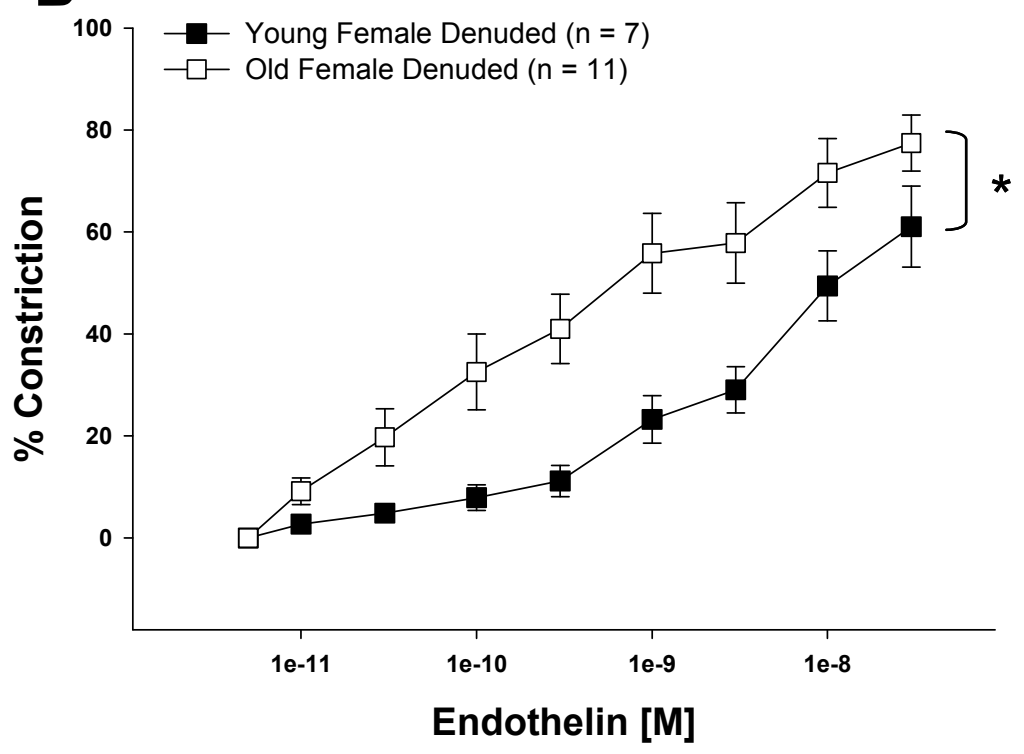

Figure 3.2. ET-induced vasoconstriction in denuded coronary arterioles from young and old males (A) and females (B). Age-related differences in vasoconstriction to ET was abolished after denudation in arterioles from males (A), but remained in arterioles from females (B). Values are means \pm SE. * Indicates significant age-related difference vs. young control, $(\mathrm{P} \leq 0.05)$. 

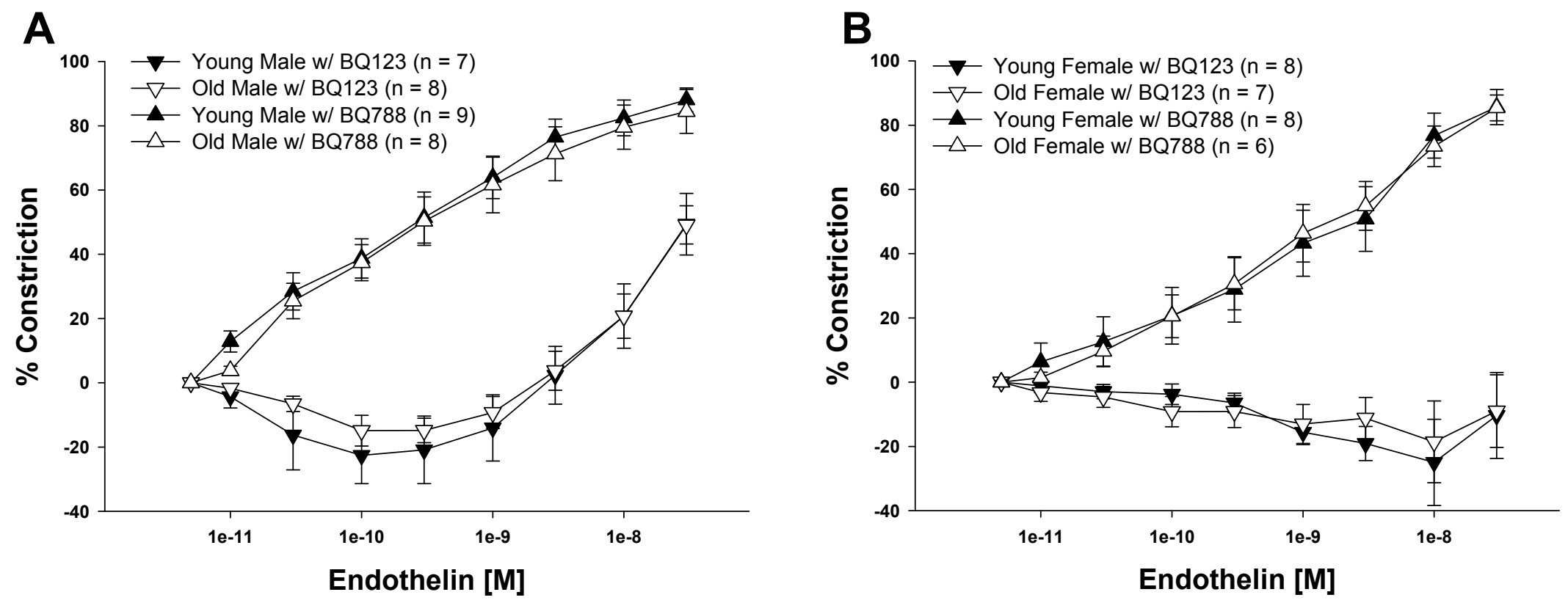


coronary arterioles from young and old males (A) and females (B). No age-related differences were found in ET-induced vasoconstriction in coronary arterioles after inhibition of ETa or ETb receptors in either sex. Values are means \pm SE. 

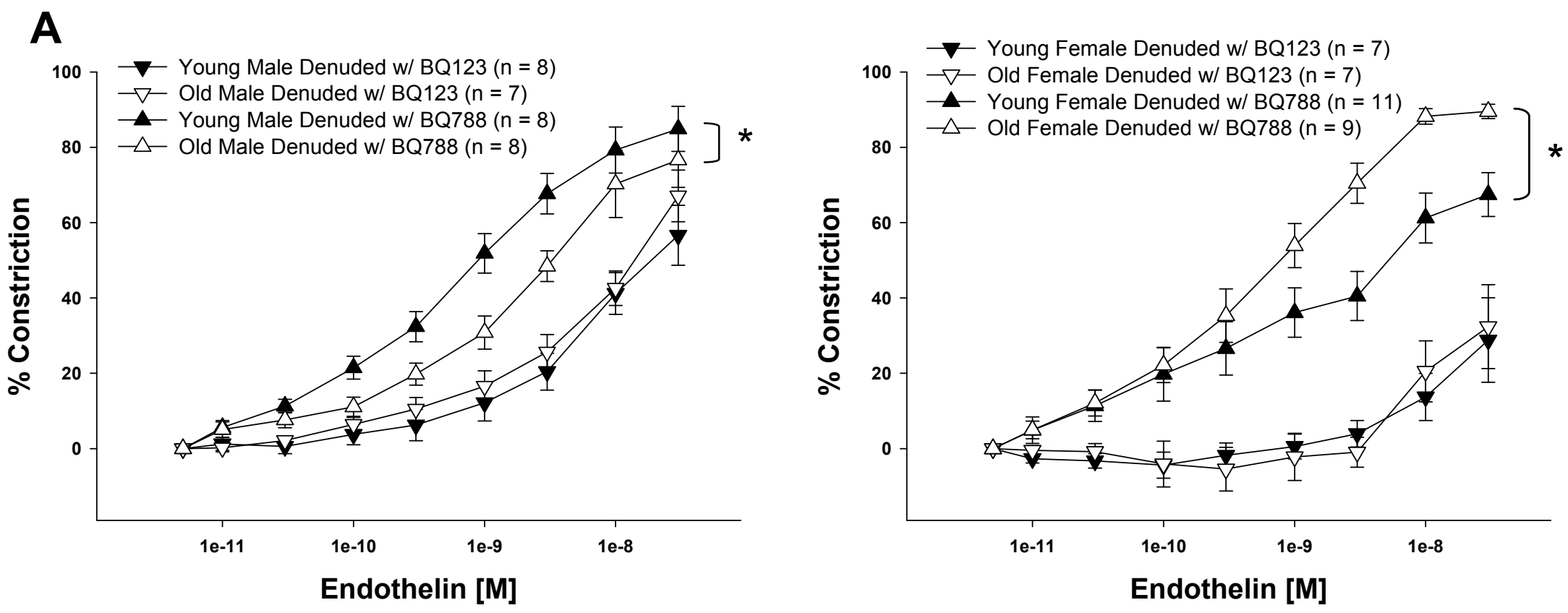

Figure 3.4. ET-induced vasoconstriction in denuded coronary arterioles after inhibition of ETa (BQ123 $\left.1 \times 10^{-6} \mathrm{M}\right)$ or ETb (BQ788 $\left.3 \times 10^{-8} \mathrm{M}\right)$ receptors in young and old males (A) and females (B). No age-related differences were found in ETb-mediated vasoconstriction in denuded coronary arterioles from either sex.

Pretreatment with BQ788 (ETb inhibitor) revealed age-related differences in the vasoconstriction to ET in males (A) and females (B). Values are means \pm SE. * Indicates significant age-related difference vs. young control, $(\mathrm{P} \leq 0.05)$. 


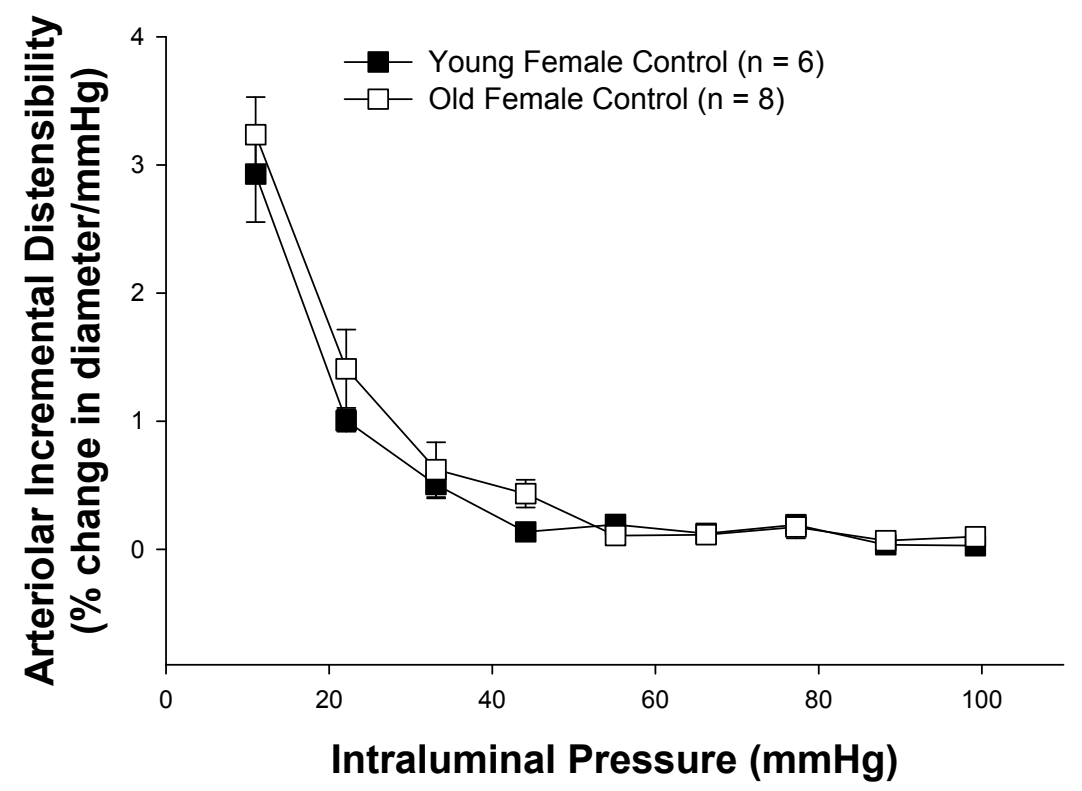

Figure 3.5. Passive distensibility curves in coronary arterioles from young and old females. There were no age-associated differences in the passive distensibility to increases in intraluminal pressure. Values are means $\pm \mathrm{SE}$. 



Figure 3.6. Both ETa and ETb mRNA expression was decreased in old males when compared to young males $(A, B)$. No age-related differences were found in ETa or ETb mRNA expression from females (C,D) ( $\mathrm{n} \geq 8$ per group). Values are means $\pm \mathrm{SE} . *$ Indicates significant age-related difference vs. young control, $(\mathrm{P} \leq 0.05)$. 



Figure 3.7. Advancing age in males caused a decrease in ETa protein expression (A), but an increase in ETb protein expression (B) in coronary arterioles (Young male, $n=4$; Old male, $n=5$ ). No age-related differences were found in ETa or ETb protein expression in coronary arterioles from females (C,D) $(n=8$ per female group). Representative blots of either ETa or ETb receptor protein ( $\sim 45 \mathrm{kd})$ are shown below graphs. Values are means $\pm \mathrm{SE}$. * Indicates significant age-related difference vs. young control, $(\mathrm{P} \leq 0.05)$. 


\section{DISCUSSION}

Coronary blood flow is meticulously regulated by the release of a combination of relaxing and constricting factors that help alter blood flow in response to changes in metabolism. ET functions as a modulator of basal vascular tone in the heart and contributes to coronary blood flow during periods of low metabolism (71). The longlasting vasoconstriction caused by ET can redirect coronary blood flow in order to promote subendocardial perfusion and has been proposed to prevent excessive back flow from the coronary circulation (71). The major finding from this study is that ET-induced vasoconstriction is differentially altered with age in coronary resistance arterioles from male and female rats (Fig 3.1). In coronary arterioles from males, the age-related decrement in ET-induced vasoconstriction is accompanied by a decrease in the expression of ETa receptor mRNA and protein (Fig 3.6 A, 3.7 A). In coronary arterioles from females, the increase in responsiveness to ET that occurs with advancing age is not associated with changes in expression of either ETa or ETb.

Considerable heterogeneity exists in the age-related response to ET in the vasculature, and depends on which specific vascular bed is being investigated. For example, a decrease (25), no change (53), or increase (26) in the vasoconstriction to ET with advancing age has been shown in mesenteric arteries, aorta, and gastrocnemius arterioles, respectively. Thus, vasoconstriction to ET varies between vessels from different vascular beds and between conduit and resistance vessels. This laboratory has previously demonstrated a decrease in vasoconstriction to ET with advancing age in coronary arterioles from male rats (97). In contrast, in large coronary arteries from aged male rats, ET-mediated vasoconstriction is increased compared to arteries from young 
rats $(50,113)$. On the other hand, whole-heart evaluations of ET-induced vasoconstriction have shown no age-related changes (34), which suggests an age-related impairment specific to the microcirculation in male hearts. This decrement in vasoconstriction to ET may contribute to altered blood flow in the hearts of senescent male rats $(42,115)$. Thus, the results show that the age-related impairment of ETinduced vasoconstriction in males is specific to coronary arterioles and does not coincide with age-related alterations in vasoconstriction to ET in larger coronary arteries from male rats.

In contrast to the male literature, there are extremely few studies regarding the age-related response to ET in any vascular bed in females. Apparently, this is the first study to investigate the effects of age on ET-mediated vasoconstriction in the coronary resistance arterioles of females. In contrast to the present finding of increased ETmediated vasoconstriction of arterioles from aged females, large epicardial arteries exhibit a decrease in maximal constriction to ET in senescent females, but this decrease in ET-mediated constriction was associated with an increase in both Big ET and functional endothelin converting enzyme (ECE) activity, two upstream regulators of endothelin production (7). In addition, age-related increases in vasoconstrictor responses to 5-HT in mesenteric arteries (109) and $\mathrm{KCl}$ and norepinephrine (NE) in aortas (7) from females have been reported, along with augmented plasma ET-1 levels in senescent females $(7,11,122)$. This suggests that females exhibit an enhanced vasoconstrictor profile along with an increase in ET levels as age progresses, and this may contribute to the heightened ET-induced vasoconstriction in coronary arterioles shown in the present study. 
Endothelin mediates its effects via two distinct G-coupled protein receptor subtypes. ETa receptors are the major subtype of receptors involved in the vasoconstrictor response to ET and are localized on the vascular smooth muscle (VSM) cell (66). ETb receptors located on the endothelial cell mediate vasodilation through the release of relaxing factors, but can exert vasoconstriction through ETb receptors located on the smooth muscle (66). Therefore, the net effect of endothelin depends on the relative distribution and density of each specific subtype of receptor. In the current study, in arterioles from both males and females, age-related differences in responses to ET remained after denuding and pretreatment with BQ-788, indicating ETa-mediated vasoconstriction is altered with advancing age (Fig 3.4). ETa mRNA and protein was decreased with old age in coronary arterioles from males and corroborates the decrement in ETa-induced vasoconstriction. In females, ETa mRNA and protein were not changed in coronary arterioles with age, suggesting that the age-related increase in ETa-mediated constriction occurs as a result of alterations in the signaling mechanisms in the VSM downstream of the receptor. Aberrant ETa-mediated constrictor responses with advancing age have been shown in coronary arteries (51) and skeletal muscle arterioles (26) in male rats; however, unlike the reduction of constriction to ET that occurs in coronary arterioles in the present study, ET-mediated constriction increases in these vascular beds with advancing age.

The ETb receptor on the endothelium is distinctive from the ET receptors on the smooth muscle due to the signaled release of relaxing factors, in particular NO (114). The endothelial ETb receptor has also been shown to modulate the vasoconstrictor effects of ET bound to ETa or ETb receptors on the vascular smooth muscle (114). In the present 
study, ETb receptor protein expression was increased with old age in males (Fig 3.7 B). However, this receptor increase cannot be ascribed to either the endothelium or VSM location because the increase in ETb receptor protein in coronary arterioles from old males may occur in both the endothelium and VSM. Seo and Luscher (94) found that stimulation of ETb receptors on the endothelium of renal arteries release more NO with advancing age in male rats; therefore, the decreased vasoconstriction to ET exhibited by aged males in the present study could be due to an increase in ETb receptor-mediated vasodilation in the endothelium. An increase in eNOS mRNA expression in coronary arterioles shown previously (97) supports the greater ETb-receptor mediated vasodilation in aged males, perhaps due to enhanced nitric oxide (NO) production from the endothelium. This is further supported by the finding that vasoconstriction to ET after denudation was increased in coronary arterioles from old versus young males, thereby abolishing age-related differences (Fig 2A). In addition, the loss of age-related differences in intact coronary arterioles in males after treatment with BQ788 suggests that the endothelial ETb receptor exerts a greater vasodilatory stimulus in coronary arterioles from aged males compared to those from young males (Fig 3.1A and Fig 3.3A). The possible increase in ETb receptor protein on the VSM in arterioles from old males may also contribute to the loss of age-related differences in coronary arterioles after denudation in males. In the current study, ET-induced vasoconstriction increased in coronary arterioles from both young and old males after denudation (Fig 3.1A and Fig 3.2A), but this increase was greater in arterioles from old males. These data indicate that the impaired vasoconstriction to ET with advancing age in coronary arterioles from males 
may be attributed to age-related modifications of the endothelium and an increase in ETb receptor number on the endothelium of coronary arterioles in male rats.

Since age-related differences in ET-mediated vasoconstriction remained after denudation in females, endothelium-independent mechanisms, such as smooth muscle mechanics and $\mathrm{Ca}^{2+}$ handling should be considered. Large arteries from female rats exhibit lower b-myosin and higher levels of sarcoplasmic reticulum $\mathrm{Ca}^{2+}$-ATPase expression compared to those from male rats (119). Lopes et al. (63) found that aged female rats exhibited an increase in colon smooth muscle contraction and suggested this might be due to increases in $\mathrm{Ca}^{2+}$ stores. Indeed, Ca-induced Ca-release is impaired in mesenteric resistance arteries from aged rats leading to an increase in stored $\mathrm{Ca}^{2+}$ content (89). In aggregate, these studies suggest that alterations in $\mathrm{Ca}^{2+}$ handling that occur with age could lead to heightened vasoconstriction to ET as seen in coronary arterioles from aged female rats.

In addition to $\mathrm{Ca}^{2+}$ alterations, $\mathrm{NO}$ feedback on ET signaling could also explain the divergent response to ET observed in aged males and females. In 1990, Boulanger and Luscher (9) first demonstrated that NO inhibits formation of ET in the aorta and suggested that an impaired release of NO from the vasculature may lead to an exaggerated ET production. In addition, NO has been shown to actively displace ET from its receptor binding site on vascular smooth muscle (33) and can directly bind to thiol groups on the ET receptor causing reduction of the thiol groups and the production of active s-nitrosothiols, a stable NO metabolite that can contribute to vasodilation (17, 101). Unpublished data from this laboratory has shown a decrement in NO-mediated vasodilation in coronary arterioles from aged females, while males exhibit an increase in 
eNOS mRNA with advancing age (97). Perhaps these opposing gender-related NO regulatory mechanisms could explain why age-associated adaptations of ET signaling are directionally opposite.

To date, there are no studies which have investigated structural adaptations in coronary arterioles of aged females. Although the present results show passive distensibility curves of coronary arterioles from young and old female rats were not significantly different (Fig 3.5), remodeling in the heart with advancing age may influence vasoreactivity of the arterial system. In humans, older women exhibit an increased augmentation index (i.e. an accepted measure of the pulsatile vascular load due to arterial stiffness and wave reflection) in carotid arteries compared to age-matched males (44). Also, a study of over 600 subjects found that arterial compliance is greater in large arteries from younger females, then diminished at the time of menopause (59). Likewise, the removal of ovarian hormones has been shown to cause an increase in left ventricle remodeling, specifically an increase in beta-myosin heavy chain isoform and collagen I/III ratio, in middle-aged females (128). However, estrogen-replacement could attenuate this remodeling (128) and favorably enhance arteriolar distensibility (21). In contrast to males, the decrease in HW/BW ratio with advancing age in females seen in the present study indicates that age-related cardiac hypertrophy does not parallel the increase in body weight exhibited throughout the female life span (Table 3.1). In total, these data indicate that the loss of estrogen with advancing age may contribute to overall cardiac remodeling and may influence the augmented response to ET in aged females.

In addition to the potential VSM effects, modulation of ET-induced constriction by endothelial factors clearly differs in arterioles from males compared to arterioles from 
females. A significant endothelial-derived constrictor influence appears to contribute to the ET-mediated vasoconstriction in coronary arterioles from both young and old females, as exhibited by a decrease in constriction induced by denudation in arterioles from both young and old females (Fig 3.1B and Fig 3.2B). In contrast, ET-induced vasoconstriction in the presence of BQ788 in intact coronary arterioles increased after denudation from old, but not young, females (Fig 3.3B and Fig 3.4B), suggesting that an endothelial dilator modulates constriction to ET in arterioles from old females. This is similar to coronary arterioles from males, in which age increases an ET-sensitive vasodilatory influence in the endothelium. In contrast to arterioles from males, the presence of an ET-sensitive endothelial vasoconstrictor appears to be unique to coronary arterioles from females. In all, age may alter vasoconstriction to ET in arterioles from females through changes in a combination of endothelial constrictor and dilator influences.

ET has been shown to be increased in chronic diseases such as congestive heart failure (68) myocardial infarction (74) and hypertension (13). Because the risk for these diseases increases with advancing age, and because these diseases are accompanied by coronary vascular dysfunction, it is imperative to determine how advancing age alters vasoreactive responses to ET of the coronary resistance vasculature. This study provides insight into the different mechanisms by which vasoconstriction to ET occurs in coronary arterioles from males and females and provides targets for future experimental approaches aimed at the endothelin-1 system. 


\section{CHAPTER IV}

\section{SUMMARY}

These two studies determined that in coronary resistance arterioles, vasoreactivity to dilating and contricting factors are altered with age in both male and female Fischer 344 rats. The first paper demonstrated that endothelium-dependent NO-mediated signaling was decreased with advancing age in coronary arterioles from females and contributes to the decrement in flow-induced vasodilation with age. This age-related impairment can be restored, however, as ovariectomy plus estrogen-replacement enhanced vasodilation to flow in coronary arterioles from senescent females compared to arterioles from old OVX and control females. This improvement in flow-induced vasodilation after estrogen-replacement in arterioles from aged females correlates to increases in phosphorylated and total eNOS protein expression.

The second paper showed that advancing age dichotomously affects vasoconstriction to endothelin in coronary arterioles from males and females. Coronary arterioles from males exhibit an age-related decline in vasoconstriction to ET which is primarily mediated through an age-related decline in ETa receptor mRNA and protein expression. In contrast, coronary arterioles from females increase ET-induced vasoconstriction with advancing age, but this is not due to age-related alterations in ETa or ETb receptor mRNA or protein expression. Instead, structural adaptations in the heart due to the decline in circulating estrogen and age-related alterations in VSM in coronary arterioles from senescent females may contribute to the increase in ET-induced vasoconstriction. 
The implications of these findings are multifold for the field of aging and the microcirculation. 1) Regardless of gender, vasodilation to flow-induced dilation is impaired in coronary arterioles with advancing age. 2) Advancing age differentially affects the vasoconstrictor responses to endothelin in coronary arterioles according to gender. 3) Perhaps most importantly is that estrogen-replacement after ovariectomy in the aged female rat improves endothelium-dependent vasodilation in coronary arterioles to levels seen in arterioles from young females. This suggests that the methodology and results of the WHI and HERS studies need to be revisited because the present data indicate a positive relationship with estrogen-replacement in the aged coronary microcirculation. It is possible that by utilizing a more optimized animal model, as in the first paper, the effects of estrogen on other vascular beds can be more accurately gauged and the combined effect of estrogen and progesterone on the risk for cardiovascular events can be investigated.

Since a release of both relaxing and constricting factors influence coronary blood flow, altered vasoreactivity with age and/or gender can significantly impede distribution and supply of blood to the subendocardium. These data suggest that age-related changes in the vasoreactivity of coronary arterioles from males and females may contribute to the increase in risk for heart failure and declining coronary flow reserve that occurs in senescent animals and humans $(19,42)$. In addition, this research has elucidated the basic mechanisms by which primary aging occurs and those which are affected by reproductive senescence. Therefore, not only is it important to consider age in future therapeutic approaches for CVD, but gender as well. 


\section{REFERENCES}

1. American College of Sports Medicine Position Stand. Exercise and physical activity for older adults. Med Sci Sports Exerc 30: 992-1008, 1998.

2. Anversa P, Li P, Sonnenblick EH, and Olivetti G. Effects of aging on quantitative structural properties of coronary vasculature and microvasculature in rats. Am J Physiol 267: H1062-1073, 1994.

3. Arbab-Zadeh A, Dijk E, Prasad A, Fu Q, Torres P, Zhang R, Thomas JD, Palmer D, and Levine BD. Effect of aging and physical activity on left ventricular compliance. Circulation 110: 1799-1805, 2004.

4. Arenas IA, Xu Y, and Davidge ST. Age-associated impairment in vasorelaxation to fluid shear stress in the female vasculature is improved by TNF-alpha antagonism. Am J Physiol Heart Circ Physiol 290: H1259-1263, 2006.

5. Arkin JM, Alsdorf R, Bigornia S, Palmisano J, Beal R, Istfan N, Hess D, Apovian CM, and Gokce N. Relation of cumulative weight burden to vascular endothelial dysfunction in obesity. Am J Cardiol 101: 98-101, 2008.

6. Armstrong SJ, Zhang Y, Stewart KG, and Davidge ST. Estrogen replacement reduces PGHS-2-dependent vasoconstriction in the aged rat. Am J Physiol Heart Circ Physiol 283: H893-898, 2002.

7. Barton M, Cosentino F, Brandes RP, Moreau P, Shaw S, and Luscher TF. Anatomic heterogeneity of vascular aging: role of nitric oxide and endothelin. Hypertension 30: 817-824, 1997.

8. Bhuiyan MS, Shioda N, and Fukunaga K. Ovariectomy augments pressure overload-induced hypertrophy associated with changes in Akt and nitric oxide synthase signaling pathways in female rats. Am J Physiol Endocrinol Metab 293: E1606-1614, 2007.

9. Boulanger C, and Luscher TF. Release of endothelin from the porcine aorta. Inhibition by endothelium-derived nitric oxide. J Clin Invest 85: 587-590, 1990.

10. Bucci M, Roviezzo F, Cicala C, Pinto A, and Cirino G. 17-beta-oestradiolinduced vasorelaxation in vitro is mediated by eNOS through hsp90 and akt/pkb dependent mechanism. Br J Pharmacol 135: 1695-1700, 2002.

11. Castellani S, Ungar A, Cantini C, La Cava G, Di Serio C, Altobelli A, Vallotti B, Pellegri M, Brocchi A, Camaiti A, Coppo M, Meldolesi U, Messeri G, and Masotti G. Excessive vasoconstriction after stress by the aging kidney: inadequate prostaglandin modulation of increased endothelin activity. J Lab Clin Med 132: 186-194, 1998.

12. Celermajer DS, Sorensen KE, Spiegelhalter DJ, Georgakopoulos D, Robinson J, and Deanfield JE. Aging is associated with endothelial dysfunction in healthy men years before the age-related decline in women. J Am Coll Cardiol 24: 471476, 1994.

13. Cernacek $\mathbf{P}$, and Stewart DJ. Immunoreactive endothelin in human plasma: marked elevations in patients in cardiogenic shock. Biochem Biophys Res Commun 161: 562-567, 1989.

14. Chen Z, Yuhanna IS, Galcheva-Gargova Z, Karas RH, Mendelsohn ME, and Shaul PW. Estrogen receptor alpha mediates the nongenomic activation of endothelial nitric oxide synthase by estrogen. J Clin Invest 103: 401-406, 1999. 
15. Chester AH, Jiang C, Borland JA, Yacoub MH, and Collins P. Oestrogen relaxes human epicardial coronary arteries through non-endothelium-dependent mechanisms. Coron Artery Dis 6: 417-422, 1995.

16. Chilian WM, Eastham CL, and Marcus ML. Microvascular distribution of coronary vascular resistance in beating left ventricle. Am J Physiol 251: H779-788, 1986. 17. Cooke JP, Stamler J, Andon N, Davies PF, McKinley G, and Loscalzo J. Flow stimulates endothelial cells to release a nitrovasodilator that is potentiated by reduced thiol. Am J Physiol 259: H804-812, 1990.

18. Csiszar A, Ungvari Z, Edwards JG, Kaminski P, Wolin MS, Koller A, and

Kaley G. Aging-induced phenotypic changes and oxidative stress impair coronary arteriolar function. Circ Res 90: 1159-1166, 2002.

19. Czernin J, Muller P, Chan S, Brunken RC, Porenta G, Krivokapich J, Chen K, Chan A, Phelps ME, and Schelbert HR. Influence of age and hemodynamics on myocardial blood flow and flow reserve. Circulation 88: 62-69, 1993.

20. de Kleijn MJ, Wilmink HW, Bots ML, Bak AA, van der Schouw YT, Planellas J, Engelen S, Banga JD, and Grobbee DE. Hormone replacement therapy and endothelial function. Results of a randomized controlled trial in healthy postmenopausal women. Atherosclerosis 159: 357-365, 2001.

21. De Meersman RE, Zion AS, Giardina EG, Weir JP, Lieberman JS, and Downey JA. Estrogen replacement, vascular distensibility, and blood pressures in postmenopausal women. Am J Physiol 274: H1539-1544, 1998.

22. Delibasi T, Kockar C, Celik A, and Kockar O. Antioxidant effects of hormone replacement therapy in postmenopausal women. Swiss Med Wkly 136: 510-514, 2006.

23. Delp MD, Evans MV, and Duan C. Effects of aging on cardiac output, regional blood flow, and body composition in Fischer-344 rats. J Appl Physiol 85: 1813-1822, 1998.

24. Dinenno FA, Jones PP, Seals DR, and Tanaka H. Limb blood flow and vascular conductance are reduced with age in healthy humans: relation to elevations in sympathetic nerve activity and declines in oxygen demand. Circulation 100: 164-170, 1999.

25. Dohi Y, and Luscher TF. Aging differentially affects direct and indirect actions of endothelin-1 in perfused mesenteric arteries of the rat. Br J Pharmacol 100: 889-893, 1990.

26. Donato AJ, Lesniewski LA, and Delp MD. The effects of aging and exercise training on endothelin-1 vasoconstrictor responses in rat skeletal muscle arterioles. Cardiovasc Res 66: 393-401, 2005.

27. Egashira K, Inou T, Hirooka Y, Kai H, Sugimachi M, Suzuki S, Kuga T, Urabe Y, and Takeshita A. Effects of age on endothelium-dependent vasodilation of resistance coronary artery by acetylcholine in humans. Circulation 88: 77-81, 1993. 28. English KM, Jones RD, Jones TH, Morice AH, and Channer KS. Aging reduces the responsiveness of coronary arteries from male Wistar rats to the vasodilatory action of testosterone. Clin Sci (Lond) 99: 77-82, 2000.

29. Florian M, Lu Y, Angle M, and Magder S. Estrogen induced changes in Aktdependent activation of endothelial nitric oxide synthase and vasodilation. Steroids 69: 637-645, 2004. 
30. Fulop T, Jebelovszki E, Erdei N, Szerafin T, Forster T, Edes I, Koller A, and

Bagi Z. Adaptation of vasomotor function of human coronary arterioles to the simultaneous presence of obesity and hypertension. Arterioscler Thromb Vasc Biol 27: 2348-2354, 2007.

31. Gilligan DM, Quyyumi AA, and Cannon RO, 3rd. Effects of physiological levels of estrogen on coronary vasomotor function in postmenopausal women. Circulation 89: 2545-2551, 1994.

32. Golding EM, and Kepler TE. Role of estrogen in modulating EDHF-mediated dilations in the female rat middle cerebral artery. Am J Physiol Heart Circ Physiol 280: H2417-2423, 2001.

33. Goligorsky MS, Tsukahara H, Magazine H, Andersen TT, Malik AB, and Bahou WF. Termination of endothelin signaling: role of nitric oxide. J Cell Physiol 158: 485-494, 1994.

34. Goodwin AT, Amrani M, Marchbank AJ, Gray CC, Jayakumar J, and Yacoub MH. Coronary vasoconstriction to endothelin-1 increases with age before and after ischaemia and reperfusion. Cardiovasc Res 41: 554-562, 1999.

35. Gordon T, Kannel WB, Hjortland MC, and McNamara PM. Menopause and coronary heart disease. The Framingham Study. Ann Intern Med 89: 157-161, 1978.

36. Grodstein F, Manson JE, Colditz GA, Willett WC, Speizer FE, and Stampfer MJ. A prospective, observational study of postmenopausal hormone therapy and primary prevention of cardiovascular disease. Ann Intern Med 133: 933-941, 2000.

37. Grodstein F, Stampfer MJ, Colditz GA, Willett WC, Manson JE, Joffe M, Rosner B, Fuchs C, Hankinson SE, Hunter DJ, Hennekens CH, and Speizer FE. Postmenopausal hormone therapy and mortality. N Engl J Med 336: 1769-1775, 1997. 38. Grodstein F, Stampfer MJ, Manson JE, Colditz GA, Willett WC, Rosner B, Speizer FE, and Hennekens CH. Postmenopausal estrogen and progestin use and the risk of cardiovascular disease. $N$ Engl J Med 335: 453-461, 1996.

39. Gruber CJ, Tschugguel W, Schneeberger C, and Huber JC. Production and actions of estrogens. $N$ Engl J Med 346: 340-352, 2002.

40. Guetta V, Quyyumi AA, Prasad A, Panza JA, Waclawiw M, and Cannon RO, 3rd. The role of nitric oxide in coronary vascular effects of estrogen in postmenopausal women. Circulation 96: 2795-2801, 1997.

41. Guo X, Razandi M, Pedram A, Kassab G, and Levin ER. Estrogen induces vascular wall dilation: mediation through kinase signaling to nitric oxide and estrogen receptors alpha and beta. J Biol Chem 280: 19704-19710, 2005.

42. Hachamovitch R, Wicker P, Capasso JM, and Anversa P. Alterations of coronary blood flow and reserve with aging in Fischer 344 rats. Am J Physiol 256: H66$73,1989$.

43. Haynes MP, Sinha D, Russell KS, Collinge M, Fulton D, Morales-Ruiz M, Sessa WC, and Bender JR. Membrane estrogen receptor engagement activates endothelial nitric oxide synthase via the PI3-kinase-Akt pathway in human endothelial cells. Circ Res 87: 677-682, 2000.

44. Hayward CS, and Kelly RP. Gender-related differences in the central arterial pressure waveform. J Am Coll Cardiol 30: 1863-1871, 1997. 
45. Headrick JP. Impact of aging on adenosine levels, A1/A2 responses, arrhythmogenesis, and energy metabolism in rat heart. Am J Physiol 270: H897-906, 1996.

46. Herrington DM, Espeland MA, Crouse JR, 3rd, Robertson J, Riley WA, McBurnie MA, and Burke GL. Estrogen replacement and brachial artery flow-mediated vasodilation in older women. Arterioscler Thromb Vasc Biol 21: 1955-1961, 2001.

47. Huang A, and Kaley G. Gender-specific regulation of cardiovascular function: estrogen as key player. Microcirculation 11: 9-38, 2004.

48. Huang A, Sun D, Wu Z, Yan C, Carroll MA, Jiang H, Falck JR, and Kaley G. Estrogen elicits cytochrome P450--mediated flow-induced dilation of arterioles in NO deficiency: role of PI3K-Akt phosphorylation in genomic regulation. Circ Res 94: 245252, 2004.

49. Hulley S, Grady D, Bush T, Furberg C, Herrington D, Riggs B, and Vittinghoff $\mathbf{E}$. Randomized trial of estrogen plus progestin for secondary prevention of coronary heart disease in postmenopausal women. Heart and Estrogen/progestin Replacement Study (HERS) Research Group. Jama 280: 605-613, 1998.

50. Ishihata A, and Katano $\mathbf{Y}$. Role of angiotensin II and endothelin-1 receptors in aging-related functional changes in rat cardiovascular system. Ann N Y Acad Sci 1067: 173-181, 2006.

51. Korzick DH, Muller-Delp JM, Dougherty P, Heaps CL, Bowles DK, and Krick KK. Exaggerated coronary vasoreactivity to endothelin-1 in aged rats: role of protein kinase C. Cardiovasc Res 66: 384-392, 2005.

52. Koyuncu FM, Ozbilgin K, Kuscu NK, Inan S, Vatansever S, and Ceylan E. The effect of oestradiol and neta on immunohistochemical staining of iNOS and eNOS in coronary arteries of ovariectomized rats. Histol Histopathol 21: 367-371, 2006.

53. Kung CF, and Luscher TF. Different mechanisms of endothelial dysfunction with aging and hypertension in rat aorta. Hypertension 25: 194-200, 1995.

54. Kuo L, Davis MJ, and Chilian WM. Endothelium-dependent, flow-induced dilation of isolated coronary arterioles. Am J Physiol 259: H1063-1070, 1990.

55. Lakatta EG. Age-associated cardiovascular changes in health: impact on cardiovascular disease in older persons. Heart Fail Rev 7: 29-49, 2002.

56. Lakatta EG. Cardiovascular ageing in health sets the stage for cardiovascular disease. Heart Lung Circ 11: 76-91, 2002.

57. Lakatta EG, and Levy D. Arterial and cardiac aging: major shareholders in cardiovascular disease enterprises: Part I: aging arteries: a "set up" for vascular disease. Circulation 107: 139-146, 2003.

58. Lakatta EG, and Levy D. Arterial and cardiac aging: major shareholders in cardiovascular disease enterprises: Part II: the aging heart in health: links to heart disease. Circulation 107: 346-354, 2003.

59. Laogun AA, and Gosling RG. In vivo arterial compliance in man. Clin Phys Physiol Meas 3: 201-212, 1982.

60. LeBlanc AJ RR, Muller-Delp JM. Beyond Venus and Mars: The effect of gender and age on endothelial dysfunction in coronary arterioles FASEB J 21:900.4: 2007. 
61. LeBlanc AJ SR, Kang LS, Muller-Delp JM. Aging Impairs Flk-1-Mediated Vasodilation in Coronary Arterioles. AJP-Heart and Circulatory Physiology In review: 2008.

62. Lieberman EH, Gerhard MD, Uehata A, Walsh BW, Selwyn AP, Ganz P, Yeung AC, and Creager MA. Estrogen improves endothelium-dependent, flowmediated vasodilation in postmenopausal women. Ann Intern Med 121: 936-941, 1994.

63. Lopes GS, Ferreira AT, Oshiro ME, Vladimirova I, Jurkiewicz NH, Jurkiewicz A, and Smaili SS. Aging-related changes of intracellular Ca2+ stores and contractile response of intestinal smooth muscle. Exp Gerontol 41: 55-62, 2006.

64. Manolio TA, Furberg CD, Shemanski L, Psaty BM, O'Leary DH, Tracy RP, and Bush TL. Associations of postmenopausal estrogen use with cardiovascular disease and its risk factors in older women. The CHS Collaborative Research Group. Circulation 88: 2163-2171, 1993.

65. Marchesi S, Vaudo G, Lupattelli G, Lombardini R, Roscini AR, Brozzetti M, Siepi D, and Mannarino E. Fat distribution and endothelial function in normaloverweight menopausal women. J Clin Pharm Ther 32: 477-482, 2007.

66. Masaki T. Possible role of endothelin in endothelial regulation of vascular tone. Annu Rev Pharmacol Toxicol 35: 235-255, 1995.

67. Maxwell SR. Women and heart disease. Basic Res Cardiol 93 Suppl 2: 79-84, 1998.

68. McMurray JJ, Ray SG, Abdullah I, Dargie HJ, and Morton JJ. Plasma endothelin in chronic heart failure. Circulation 85: 1374-1379, 1992.

69. McNeill AM, Kim N, Duckles SP, Krause DN, and Kontos HA. Chronic estrogen treatment increases levels of endothelial nitric oxide synthase protein in rat cerebral microvessels. Stroke 30: 2186-2190, 1999.

70. Mendelsohn ME, and Karas RH. The protective effects of estrogen on the cardiovascular system. $N$ Engl J Med 340: 1801-1811, 1999.

71. Merkus D, Brzezinska AK, Zhang C, Saito S, and Chilian WM. Cardiac myocytes control release of endothelin-1 in coronary vasculature. Am J Physiol Heart Circ Physiol 288: H2088-2092, 2005.

72. Merkus D, Duncker DJ, and Chilian WM. Metabolic regulation of coronary vascular tone: role of endothelin-1. Am J Physiol Heart Circ Physiol 283: H1915-1921, 2002.

73. Mickley EJ, Gray GA, and Webb DJ. Activation of endothelin ETA receptors masks the constrictor role of endothelin ETB receptors in rat isolated small mesenteric arteries. Br J Pharmacol 120: 1376-1382, 1997.

74. Miyauchi T, Yanagisawa M, Tomizawa T, Sugishita Y, Suzuki N, Fujino M, Ajisaka R, Goto K, and Masaki T. Increased plasma concentrations of endothelin-1 and big endothelin-1 in acute myocardial infarction. Lancet 2: 53-54, 1989.

75. Moien-Afshari F, Kenyon E, Choy JC, Battistini B, McManus BM, and

Laher I. Long-term effects of ovariectomy and estrogen replacement treatment on endothelial function in mature rats. Maturitas 45: 213-223, 2003.

76. Momoi H, Ikomi F, and Ohhashi T. Estrogen-induced augmentation of endothelium-dependent nitric oxide-mediated vasodilation in isolated rat cerebral small arteries. Jpn J Physiol 53: 193-203, 2003. 
77. Muller-Delp JM, Lubahn DB, Nichol KE, Philips BJ, Price EM, Curran EM, and Laughlin MH. Regulation of nitric oxide-dependent vasodilation in coronary arteries of estrogen receptor-alpha-deficient mice. Am J Physiol Heart Circ Physiol 285: H2150-2157, 2003.

78. Muller-Delp JM, Spier SA, Ramsey MW, and Delp MD. Aging impairs endothelium-dependent vasodilation in rat skeletal muscle arterioles. Am J Physiol Heart Circ Physiol 283: H1662-1672, 2002.

79. Murohara T, Yasue H, Ohgushi M, Sakaino N, and Jougasaki M. Age related attenuation of the endothelium dependent relaxation to noradrenaline in isolated pig coronary arteries. Cardiovasc Res 25: 1002-1009, 1991.

80. Nawate S, Fukao M, Sakuma I, Soma T, Nagai K, Takikawa O, Miwa S, and Kitabatake A. Reciprocal changes in endothelium-derived hyperpolarizing factor- and nitric oxide-system in the mesenteric artery of adult female rats following ovariectomy. Br J Pharmacol 144: 178-189, 2005.

81. New G, Duffy SJ, Harper RW, and Meredith IT. Long-term oestrogen therapy is associated with improved endothelium-dependent vasodilation in the forearm resistance circulation of biological males. Clin Exp Pharmacol Physiol 27: 25-33, 2000. 82. Ouyang P, Michos ED, and Karas RH. Hormone replacement therapy and the cardiovascular system lessons learned and unanswered questions. J Am Coll Cardiol 47: 1741-1753, 2006.

83. Parker BA, Ridout SJ, and Proctor DN. Age and flow-mediated dilation: a comparison of dilatory responsiveness in the brachial and popliteal arteries. Am J Physiol Heart Circ Physiol 291: H3043-3049, 2006.

84. Pelligrino DA, Ye S, Tan F, Santizo RA, Feinstein DL, and Wang Q. Nitricoxide-dependent pial arteriolar dilation in the female rat: effects of chronic estrogen depletion and repletion. Biochem Biophys Res Commun 269: 165-171, 2000.

85. Prisby RD, Muller-Delp J, Delp MD, and Nurkiewicz TR. Age, gender, and hormonal status modulate the vascular toxicity of the diesel exhaust extract phenanthraquinone. J Toxicol Environ Health A 71: 464-470, 2008.

86. Rahimian R, Dube GP, Toma W, Dos Santos N, McManus BM, and van Breemen C. Raloxifene enhances nitric oxide release in rat aorta via increasing endothelial nitric oxide mRNA expression. Eur J Pharmacol 434: 141-149, 2002. 87. Rossouw JE, Anderson GL, Prentice RL, LaCroix AZ, Kooperberg C, Stefanick ML, Jackson RD, Beresford SA, Howard BV, Johnson KC, Kotchen JM, and Ockene $\mathbf{J}$. Risks and benefits of estrogen plus progestin in healthy postmenopausal women: principal results From the Women's Health Initiative randomized controlled trial. Jama 288: 321-333, 2002.

88. Rossouw JE, Prentice RL, Manson JE, Wu L, Barad D, Barnabei VM, Ko M, LaCroix AZ, Margolis KL, and Stefanick ML. Postmenopausal hormone therapy and risk of cardiovascular disease by age and years since menopause. Jama 297: 1465-1477, 2007.

89. Rubio C, Moreno A, Briones A, Ivorra MD, D'Ocon P, and Vila E.

Alterations by age of calcium handling in rat resistance arteries. J Cardiovasc Pharmacol 40: 832-840, 2002.

90. Saitta A, Altavilla D, Cucinotta D, Morabito N, Frisina N, Corrado F, D'Anna R, Lasco A, Squadrito G, Gaudio A, Cancellieri F, Arcoraci V, and 
Squadrito F. Randomized, double-blind, placebo-controlled study on effects of raloxifene and hormone replacement therapy on plasma no concentrations, endothelin-1 levels, and endothelium-dependent vasodilation in postmenopausal women. Arterioscler Thromb Vasc Biol 21: 1512-1519, 2001.

91. Sakuma I, Liu MY, Sato A, Hayashi T, Iguchi A, Kitabatake A, and Hattori $\mathbf{Y}$. Endothelium-dependent hyperpolarization and relaxation in mesenteric arteries of middle-aged rats: influence of oestrogen. Br J Pharmacol 135: 48-54, 2002.

92. Schindler TH, Cardenas J, Prior JO, Facta AD, Kreissl MC, Zhang XL, Sayre J, Dahlbom M, Licinio J, and Schelbert HR. Relationship between increasing body weight, insulin resistance, inflammation, adipocytokine leptin, and coronary circulatory function. J Am Coll Cardiol 47: 1188-1195, 2006.

93. Schulz E, Anter E, Zou MH, and Keaney JF, Jr. Estradiol-mediated endothelial nitric oxide synthase association with heat shock protein 90 requires adenosine monophosphate-dependent protein kinase. Circulation 111: 3473-3480, 2005. 94. Seo B, and Luscher TF. ETA and ETB receptors mediate contraction to endothelin-1 in renal artery of aging SHR. Effects of FR139317 and bosentan. Hypertension 25: 501-506, 1995.

95. Shaw L, Taggart MJ, and Austin C. Mechanisms of 17 beta-oestradiol induced vasodilatation in isolated pressurized rat small arteries. Br J Pharmacol 129: 555-565, 2000.

96. Shipley RD, Kim SJ, and Muller-Delp JM. Time course of flow-induced vasodilation in skeletal muscle: contributions of dilator and constrictor mechanisms. Am J Physiol Heart Circ Physiol 288: H1499-1507, 2005.

97. Shipley RD, and Muller-Delp JM. Aging decreases vasoconstrictor responses of coronary resistance arterioles through endothelium-dependent mechanisms. Cardiovasc Res 66: 374-383, 2005.

98. Simoncini T, Hafezi-Moghadam A, Brazil DP, Ley K, Chin WW, and Liao JK. Interaction of oestrogen receptor with the regulatory subunit of phosphatidylinositol3-OH kinase. Nature 407: 538-541, 2000.

99. Simoncini T, Rabkin E, and Liao JK. Molecular basis of cell membrane estrogen receptor interaction with phosphatidylinositol 3-kinase in endothelial cells. Arterioscler Thromb Vasc Biol 23: 198-203, 2003.

100. Stallone JN, Crofton JT, and Share L. Sexual dimorphism in vasopressininduced contraction of rat aorta. Am J Physiol 260: H453-458, 1991.

101. Stamler JS, Simon DI, Osborne JA, Mullins ME, Jaraki O, Michel T, Singel DJ, and Loscalzo J. S-nitrosylation of proteins with nitric oxide: synthesis and characterization of biologically active compounds. Proc Natl Acad Sci U S A 89: 444448, 1992.

102. Stampfer MJ, Colditz GA, Willett WC, Manson JE, Rosner B, Speizer FE, and Hennekens CH. Postmenopausal estrogen therapy and cardiovascular disease. Tenyear follow-up from the nurses' health study. $N$ Engl J Med 325: 756-762, 1991.

103. Stewart KG, Zhang Y, and Davidge ST. Aging increases PGHS-2-dependent vasoconstriction in rat mesenteric arteries. Hypertension 35: 1242-1247, 2000.

104. Sugishita K, Li F, Su Z, and Barry WH. Anti-oxidant effects of estrogen reduce [Ca2+]i during metabolic inhibition. J Mol Cell Cardiol 35: 331-336, 2003. 
105. Sun D, Huang A, Yan EH, Wu Z, Yan C, Kaminski PM, Oury TD, Wolin MS, and Kaley G. Reduced release of nitric oxide to shear stress in mesenteric arteries of aged rats. Am J Physiol Heart Circ Physiol 286: H2249-2256, 2004.

106. Swine C. [Aging of heart function in man]. Presse Med 21: 1216-1221, 1992.

107. Swinne CJ, Shapiro EP, Lima SD, and Fleg JL. Age-associated changes in left ventricular diastolic performance during isometric exercise in normal subjects. Am J Cardiol 69: 823-826, 1992.

108. Taddei S, Virdis A, Ghiadoni L, Mattei P, Sudano I, Bernini G, Pinto S, and

Salvetti A. Menopause is associated with endothelial dysfunction in women.

Hypertension 28: 576-582, 1996.

109. Tatchum-Talom R, and Martin DS. Tempol improves vascular function in the mesenteric vascular bed of senescent rats. Can J Physiol Pharmacol 82: 200-207, 2004.

110. Tawfik HE, Teng B, Morrison RR, Schnermann J, and Mustafa SJ. Role of A1 adenosine receptor in the regulation of coronary flow. Am J Physiol Heart Circ Physiol 291: H467-472, 2006.

111. Thom T, Haase N, Rosamond W, Howard VJ, Rumsfeld J, Manolio T, Zheng ZJ, Flegal K, O'Donnell C, Kittner S, Lloyd-Jones D, Goff DC, Jr., Hong Y, Adams R, Friday G, Furie K, Gorelick P, Kissela B, Marler J, Meigs J, Roger V, Sidney S, Sorlie $\mathbf{P}$, Steinberger J, Wasserthiel-Smoller S, Wilson M, and Wolf P. Heart disease and stroke statistics--2006 update: a report from the American Heart Association Statistics Committee and Stroke Statistics Subcommittee. Circulation 113: e85-151, 2006.

112. Thompson LP, Pinkas G, and Weiner CP. Chronic 17beta-estradiol replacement increases nitric oxide-mediated vasodilation of guinea pig coronary microcirculation. Circulation 102: 445-451, 2000.

113. Tschudi MR, and Luscher TF. Age and hypertension differently affect coronary contractions to endothelin-1, serotonin, and angiotensins. Circulation 91: 2415-2422, 1995.

114. Tsukahara H, Ende H, Magazine HI, Bahou WF, and Goligorsky MS. Molecular and functional characterization of the non-isopeptide-selective ETB receptor in endothelial cells. Receptor coupling to nitric oxide synthase. J Biol Chem 269: 2177821785, 1994.

115. Tuma RF, Irion GL, Vasthare US, and Heinel LA. Age-related changes in regional blood flow in the rat. Am J Physiol 249: H485-491, 1985.

116. Unverferth DV, Fetters JK, Unverferth BJ, Leier CV, Magorien RD, Arn AR, and Baker PB. Human myocardial histologic characteristics in congestive heart failure. Circulation 68: 1194-1200, 1983.

117. Wagner JD, and Clarkson TB. The applicability of hormonal effects on atherosclerosis in animals to heart disease in postmenopausal women. Semin Reprod Med 23: 149-156, 2005.

118. Wang Y, Kanatsuka H, Akai K, Sugimura A, Kumagai T, Komaru T, Sato $\mathbf{K}$, and Shirato K. Effects of low doses of endothelin-1 on basal vascular tone and autoregulatory vasodilation in canine coronary microcirculation in vivo. Jpn Circ J 63: 617-623, 1999. 
119. Weinberg EO, Thienelt CD, Katz SE, Bartunek J, Tajima M, Rohrbach S, Douglas PS, and Lorell BH. Gender differences in molecular remodeling in pressure overload hypertrophy. J Am Coll Cardiol 34: 264-273, 1999.

120. Weisfeldt ML, Wright JR, Shreiner DP, Lakatta E, and Shock NW. Coronary flow and oxygen extraction in the perfused heart of senescent male rats. J Appl Physiol 30: 44-49, 1971.

121. Wellman GC, Bonev AD, Nelson MT, and Brayden JE. Gender differences in coronary artery diameter involve estrogen, nitric oxide, and $\mathrm{Ca}(2+)$-dependent $\mathrm{K}+$ channels. Circ Res 79: 1024-1030, 1996.

122. White M, Courtemanche M, Stewart DJ, Talajic M, Mikes E, Cernacek P, Vantrimpont P, Leclerc D, Bussieres L, and Rouleau JL. Age- and gender-related changes in endothelin and catecholamine release, and in autonomic balance in response to head-up tilt. Clin Sci (Lond) 93: 309-316, 1997.

123. White RE, Han G, Dimitropoulou C, Zhu S, Miyake K, Fulton D, Dave S, and Barman SA. Estrogen-induced contraction of coronary arteries is mediated by superoxide generated in vascular smooth muscle. Am J Physiol Heart Circ Physiol 289: H1468-1475, 2005.

124. Williams JK, Adams MR, and Klopfenstein HS. Estrogen modulates responses of atherosclerotic coronary arteries. Circulation 81: 1680-1687, 1990.

125. Woodman CR, Price EM, and Laughlin MH. Aging induces muscle-specific impairment of endothelium-dependent dilation in skeletal muscle feed arteries. J Appl Physiol 93: 1685-1690, 2002.

126. Woodman CR, Price EM, and Laughlin MH. Shear stress induces eNOS mRNA expression and improves endothelium-dependent dilation in senescent soleus muscle feed arteries. J Appl Physiol 98: 940-946, 2005.

127. Xu HL, Santizo RA, Baughman VL, and Pelligrino DA. Nascent EDHFmediated cerebral vasodilation in ovariectomized rats is not induced by eNOS dysfunction. Am J Physiol Heart Circ Physiol 285: H2045-2053, 2003.

128. Xu Y, Arenas IA, Armstrong SJ, and Davidge ST. Estrogen modulation of left ventricular remodeling in the aged heart. Cardiovasc Res 57: 388-394, 2003.

129. Yamaguchi K, Honda H, Wakisaka C, Tohei A, and Kogo H. Effects of phytoestrogens on acetylcholine- and isoprenaline-induced vasodilation in rat aorta. Jpn J Pharmacol 87: 67-73, 2001. 


\section{APPENDIX}


C Flow (nl/sec)

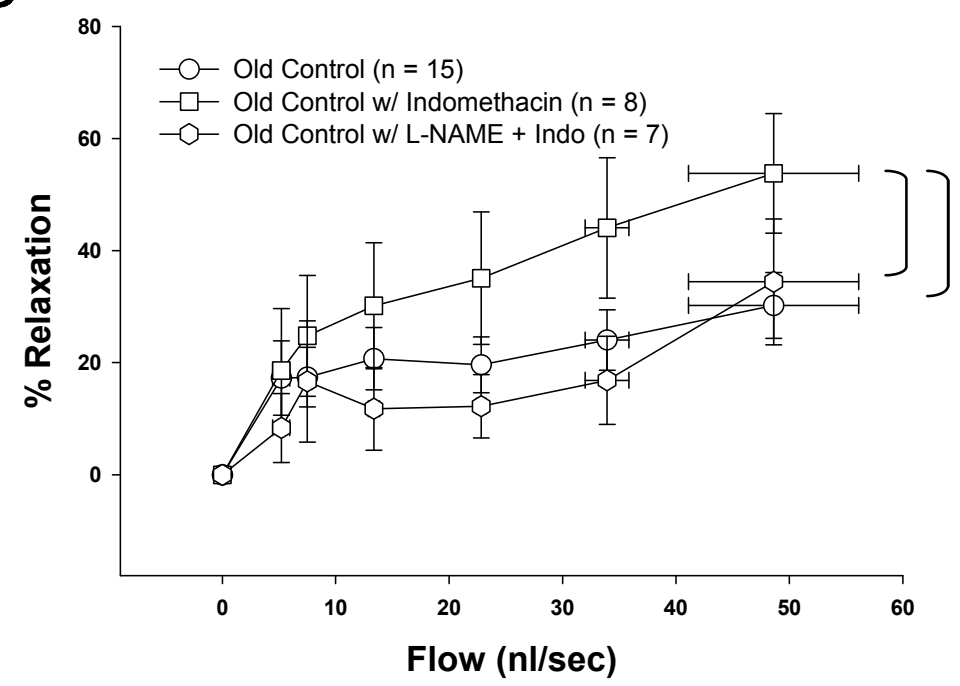






J
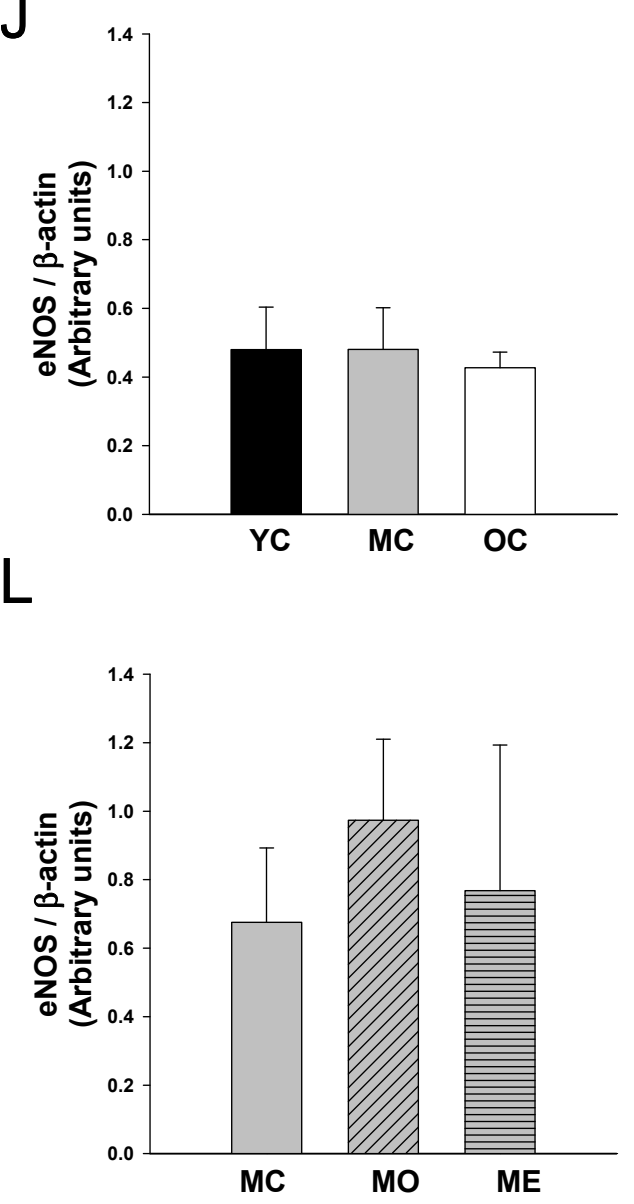
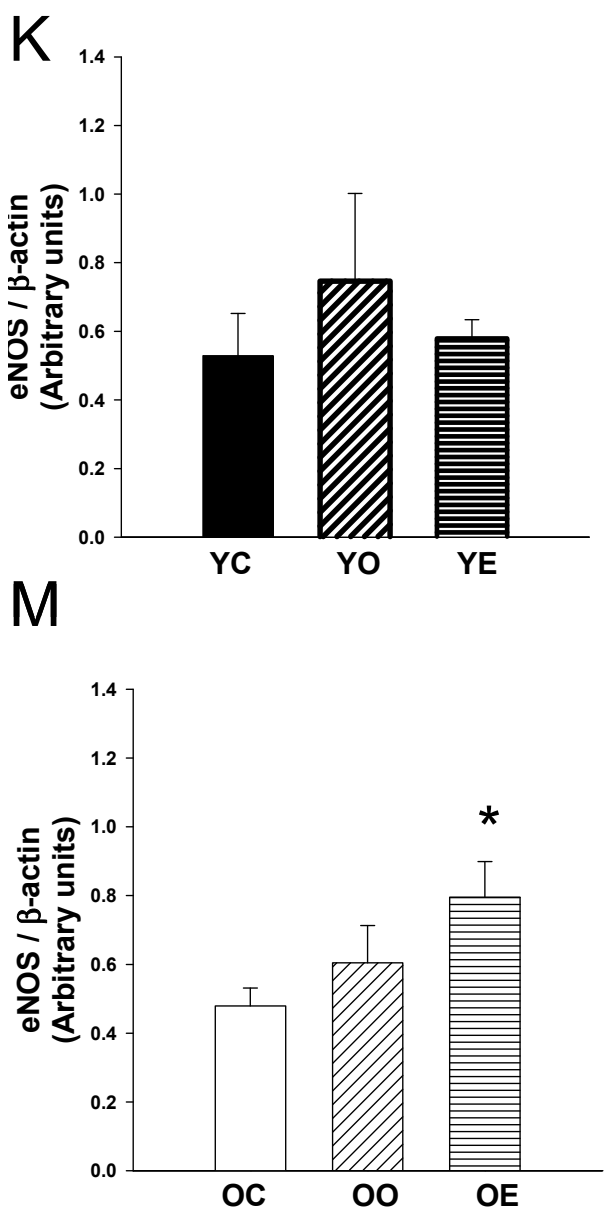

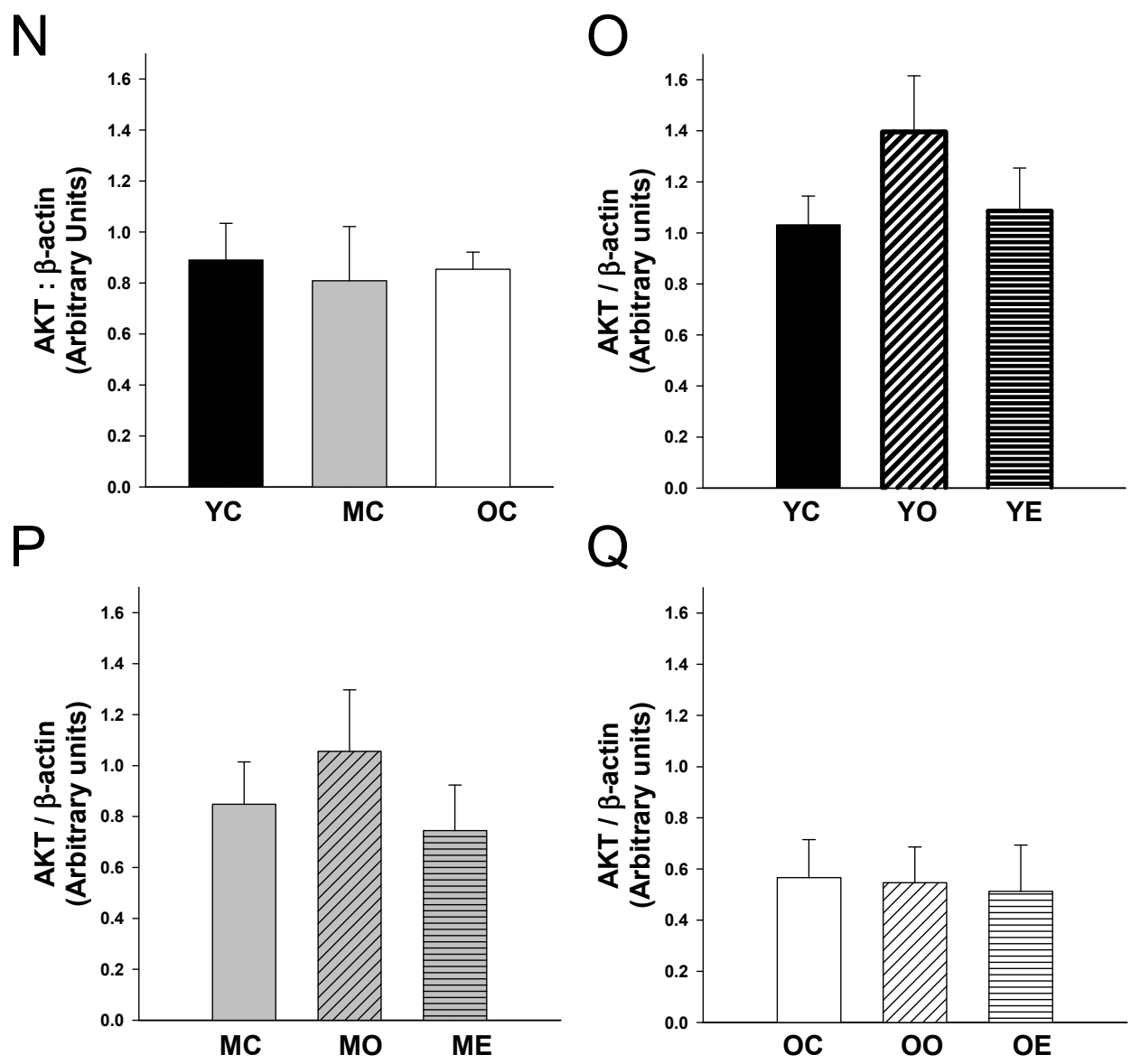
Amanda Jo LeBlanc

\section{PRESENT POSITION AND ADDRESS: \\ Position: Postdoctoral Assistant \\ Office: Department of Physiology \\ School of Medicine \\ Robert C. Byrd Health Sciences Center \\ Morgantown, West Virginia, 26506}

Phone: $\quad$ (304) 293-1007

Fax: (304) 293-5513

Email: aleblanc@hsc.wvu.edu

Home: $\quad 307 \mathrm{C}$ Duquesne St

Morgantown, WV 26505

Phone: (502) 468-8227

PERSONAL DATA:

Birthdate: $\quad$ August 7, 1981

Place of Birth: Jeffersonville, IN

EDUCATION AND TRAINING

Degree/Training Institution Field Dates

B.S. Indiana University $\quad$ Exercise Science August 2002

M.S. University of Louisville Exercise Physiology May 2004

Ph.D. West Virginia University Exercise Physiology August 2008

\section{PROFESSIONAL EXPERIENCE AND ACADEMIC APPOINTMENTS}

1999-2002: Laboratory Technician, Geo. Pfau Sons Co., Jeffersonville, Indiana

2004-05: Graduate Teaching Assistant, Texas A\&M University, College Station, Texas

2005-08: Graduate Assistant, West Virginia University, Morgantown, WV

Microdissection and cannulation of coronary arterioles, RT-PCR and Western blot experience

SOCIETY MEMBERSHIPS

American Physiological Society (2005-present)

American Microcirculatory Society (2005-present) 


\section{AWARDS AND HONORS}

2002: $\quad$ Graduated with distinction, Indiana University

2007: $\quad$ American Physiological Society CV Section Research Recognition Award

2007: $\quad$ First Place Poster Presentation, E.J. Van Liere Research Day, West

Virginia University

2007: $\quad$ Third Place Oral Presentation, E.J. Van Liere Convocation, West Virginia

University

2007: $\quad 8^{\text {th }}$ World Congress for Microcirculation Zweifach Student Travel Award

TEACHING EXPERIENCE (* graduate level)

$\begin{array}{llll}\begin{array}{c}\text { Course Title } \\ \text { Dates } \\ \text { Health and Fitness }\end{array} & \text { Institution } & \text { Credit Hr } & \text { Contact Hr } \\ 2005 & \text { Texas A\&M } & 1 & 2 \mathrm{hrs} / \mathrm{wk}\end{array}$

\section{BIBLIOGRAPHY}

Refereed Research Papers:

LeBlanc AJ, Shipley RD, Muller-Delp JM. Flk-1 impairment decreases vasodilation in coronary arterioles. In revision to AJP-Heart Circ

LeBlanc AJ, PJ Dougherty, RA Reyes, RD Shipley, X Jiang, DH Korzick, JM MullerDelp. Aging and gender effects on vasoconstriction to endothelin in coronary arterioles. Submitted

LeBlanc AJ, Rafael Reyes, Lori S. Kang, John N. Stallone, Judy M. Muller-Delp. Estrogen replacement improves while aging and loss of ovarian hormones impair flowinduced vasodilation in coronary arterioles. Submitted to AJP-Endocrinology

Presentations:

LeBlanc AJ, and Muller-Delp JM. "Age-induced impairment of nitric oxide-dependent vasodilation in coronary arterioles: Role of phosphotidylinositol 3-kinase signaling". A Special Transatlantic Meeting of The Microcirculatory Society, Inc. and The British Microcirculation Society, Durham, NH, September 2005

LeBlanc AJ, and Muller-Delp JM. "Beyond Venus and Mars: The effect of gender and age on endothelial dysfunction in coronary arterioles". E.J. Van Liere Convocation, West Virginia University, April, 2007 
LeBlanc AJ, Reyes RA, and Muller-Delp JM. "Beyond Venus and Mars: The effect of gender and age on endothelial dysfunction in coronary arterioles". FASEB, Washington D.C., May, 2007

Abstracts:

LeBlanc AJ, Shipley RD, and Muller-Delp JM. Effect of aging on nitric oxide signaling in coronary arterioles: Role of phosphoinositol 3-kinase. FASEB J 20: A1397, 2006.

LeBlanc AJ, Nichol KE, Woodman CR, Shipley RD, Prisby RD, and Muller-Delp JM. NOS expression and activity in cerebral resistance arteries: Effects of aging and exercise training. FASEB J 20: A813, 2006.

LeBlanc AJ, Behnke BJ, Wu G, Muller-Delp JM, DelpMD. Aging Decreases NOS Regulatory Mechanisms in Skeletal Muscle Resistance Arteries. Med Sci Sports Exercise 38(11) Suppl 1:S3, 2006.

Reyes RA, Nichol KE, Spier SA, LeBlanc AJ, Muller-Delp, JM. Effects of Age and Exercise Training on Nitric Oxide Bioavailability in Cerebral Resistance Arteries. Med Sci Sports Exercise 38(11) Suppl 1:S4, 2006.

Casey McCroskey, Rafael Antonio Reyes, Amanda Jo LeBlanc, and Judy Muller-Delp; Endothelial-dependent and -independent vasodilation in cerebral resistance arteries: Effects of age and estrogen Status FASEB J. 2007 21:904.9

Amanda Jo LeBlanc, Rafael Reyes, and Judy M. Muller-Delp; Beyond Venus and Mars: The effect of gender and age on endothelial dysfunction in coronary arterioles FASEB J. 2007 21:900.4

Rafael Antonio Reyes, Amanda Jo LeBlanc, and Judy Muller-Delp; Thromboxane induced-vasoconstriction in coronary resistance arteries: Effects of age and ovarian hormone status FASEB J. 2007 21:740.12

Lori Sunhae Kang, Amanda Jo LeBlanc, Patrick James Dougherty, Robert Shipley, and Judy Marie Muller-Delp; Aging and gender alter thromboxane-induced vasoconstriction and thromboxane receptor expression in coronary microvasculature FASEB J. 2007 21:740.11

Amanda Jo LeBlanc, Rafael Reyes, and Judy M Muller-Delp; Advancing age and loss of ovarian hormones impair flow-induced dilation in the female coronary microvasculature FASEB J. 2008 22:1142.7 